\title{
Effects of Landslides on the Displacement of a Bridge Pile Group Located on a High and Steep Slope
}

\author{
Y. F. Zhang, ${ }^{1}$ J. Li ${ }^{1},{ }^{1}$ W. Li, ${ }^{1,2}$ J. M. Li, ${ }^{1,2}$ and H. Y. Liu ${ }^{1,3}$ \\ ${ }^{1}$ Railway Engineering Research Institute, China Academy of Railway Sciences Group Co., Ltd., Beijing 100081, China \\ ${ }^{2}$ Beijing Tieke Engineering Inspection Co., Ltd., Beijing 100081, China \\ ${ }^{3}$ School of Energy and Mining Engineering, China University of Mining and Technology (Beijing), Beijing 100083, China
}

Correspondence should be addressed to J. Li; ljbk911@126.com

Received 15 December 2020; Revised 18 April 2021; Accepted 27 May 2021; Published 1 July 2021

Academic Editor: Morteza Bagherpour

Copyright $\odot 2021$ Y. F. Zhang et al. This is an open access article distributed under the Creative Commons Attribution License, which permits unrestricted use, distribution, and reproduction in any medium, provided the original work is properly cited.

\begin{abstract}
Engineering practice shows that the deformation of the slide-resistant pile may be transferred to the adjacent bridge foundation on an inclined slope, which can compromise the safety of the entire bridge. However, this phenomenon has rarely been considered in the past. To reveal the deformation transfer mechanism between the slide-resistant pile and the adjacent structures, a full-scale field test was performed on a high and steep slope located in a section of a certain railway. A numerical analysis model was constructed to simulate the field test and validate its parameters. Moreover, parametric analysis was also conducted to examine the influence of the pile length, pile diameter, and arrangement of the pile foundation. The results show that the bridge pile foundation is simultaneously affected by the "load transfer effect" caused by the slide-resistant pile and "traction effect" of the sliding slope. With the distance between the pile foundation and the slideresistant pile increasing, the dominant factor affecting the deformation mode of the pile body is switched from the "load transfer effect" to the "traction effect." Furthermore, a critical embedment depth exists for the bridge pile foundation built on a high and steep slope, which varies at different locations along the inclined stratum. In addition, using a pile arrangement with a larger pile diameter and lower number of piles is more beneficial for controlling the horizontal displacement of the bridge foundation. The results of the research provide a reference for the safety control of the engineering on the high and steep slope.
\end{abstract}

\section{Introduction}

Owing to the limitations caused by local terrains, the construction of railways and highways on hilly terrains or in mountainous areas often requires the route to pass through regions with adverse geological conditions such as landslide masses. As an example, the bridges built on the top of sliding masses face a series of potential hazards including the pier displacement under the force of a landslide. These hazards significantly affect the service life of a bridge structure and may even result in the occurrence of serious engineering disasters $[1,2]$.

One such disaster produced by a severe landslide with a length of $200 \mathrm{~m}$ and width of $100 \mathrm{~m}$ occurred on April 25, 2010, in Keelung. The entire mass of the landslide slid onto a highway causing the collapse of the Dapu Bridge [3]. In another incident, a large-scale landslide with a total volume of around $30,000 \mathrm{~m}^{3}$ occurred on Pingru Highway, Hunan Province of China, on May 22, 2016, due to continuous rainfall. It caused a horizontal displacement of the upper bridge structure and blockage of the two-way road traffic [4].

Currently, the focus of the transportation infrastructure construction in China is gradually moving towards the central and western regions that share some common geographical features such as a diverse climate, a large number of mountains with mid-to-high altitudes, and complex geological and geomorphological characteristics. Therefore, the design, construction, and post-management of bridges in these regions must be conducted more thoroughly. In many cases, the routes selected for constructing high-grade roads and railways in mountainous areas are unique (in other words, not many alternative options are available for their construction). Usually, a route lies along either a riverside or a mountainside where landslides are 
more likely to occur. In recent years, a relatively large number of bridge defects and disasters were caused by landslides leading to significant economic losses.

The slide-resistant pile is an effective structure to prevent landslides. Therefore, the design method of slide-resistant pile has been researched extensively. Some of the major research works in that area included analytical research [5-7], numerical simulations [8-11], and experimental and field tests [12-14]. During this year, several new types of slide-resistant piles such as h-type [15] and group [9] ones were proposed. However, large-scale field tests that can provide valuable data on the working characteristics of slideresistant piles are seldom presented.

Besides, the majority of the aforementioned studies focused on the stability of the slope, while the deformation of the structure to be protected (e.g., bridge structure on the slope) has received only limited attention. In reality, a bridge structure may be adjacent to a slide-resistant pile and located on the inclined slope due to the constraints of various engineering conditions. In this case, the deformation of the slide-resistant pile may be transferred to the bridge foundation, thus compromising the safety of the entire bridge. Therefore, the deformation analysis of the structure on the slope becomes more significant, besides the stability analysis.

The behavior of the bridge pile foundation on a high and steep slope is very complex. Such a foundation is typically subjected to both the oblique and vertical loads transferred from its superstructure. The horizontal loads of bridge pile foundations have been explored in many studies including scale model experiments [16-19] and centrifugal experiments [20,21]. These works focused on analyzing the p-y curves recorded under horizontal loads and deformation patterns of the pile foundation, and stiffness of the bridge pile. However, the stress level in a stratum and distribution of the strata used in scaled model experiments are different from those utilized in real engineering projects. Different types of analytical analysis [22] and numerical simulation methods [23-25] have been proposed by various researchers. In addition, the stresses of bridge piles generated under various extreme conditions (including rainstorms and earthquakes) have also been investigated by conducting numerical simulations [26-29]. However, full-scale field tests for investigating the stress generated in bridge pile foundations on high and steep slopes have not been conducted yet. The only related field tests were performed to measure the horizontal loads of the pile foundations on a horizontal stratum [30,31]. Hence, the loading behavior of the pile foundations on inclined strata (in particular, the displacement transfer from the slide-resistant pile to the adjacent bridge piles) remains unexplored. Typical studies and the research gap are summarized in Table 1.

In this study, a full-scale field test was performed on a high and steep slope located in a section of the railway. Its objective was to determine the loading behavior and deformation patterns of the pile group foundation on an inclined stratum subjected to the horizontal force caused by a landslide. As a result, displacement transfer coefficients of the slide-resistant pile and bridge pile foundation were obtained. In addition, a numerical analysis model was constructed to simulate the conducted field test and validate its parameters. The latter was utilized to investigate the deformation and stress characteristics of the bridge pile foundation on the high and steep slope under extreme conditions by numerical analysis. Meanwhile, parametric analysis was also conducted to examine the influence of the pile length, pile diameter, and the piling process on the pile foundation.

\section{Site Conditions}

The railway runs across three major fault zones. Their topographical and geological conditions are extremely complex due to the high seismic activity, landslides, and talus. A bridge over the railway is located at the foot of an adverse geological body. The main structure of the bridge occupies the middle and lower parts of the landslide mass, and the sliding direction is perpendicular to the route. Therefore, landslides pose a huge safety threat to the bridge, as shown in Figure 1.

Figure 2 describes the parameters of the rock layer and the structure of a typical section $(\mathrm{O}-\mathrm{O})$. The stratum is composed of coarse breccia, gravelly soil, strongly weathered slate, and moderately weathered slate from the top to the bottom. The physical and mechanical parameters of the rock (soil) are listed in Table 2.

As shown in Figure 2, the pile foundation of the bridge is located at the foot of the sliding mass. Two rows of slide-resistant piles are arranged in this section. Among them, 29\# is the first row of the slide-resistant piles with a length of $47 \mathrm{~m}$ and cross section size of $4 \mathrm{~m} \times 3 \mathrm{~m}$, which also serves as a retaining structure. Three prestressed anchor cables are deployed from the pile top to the bottom. The second row of the slide-resistant pile is $66 \#$ with a length of $41 \mathrm{~m}$ and cross section size of $3.5 \mathrm{~m} \times 3 \mathrm{~m}$.

Owing to the limited route selection, the foundation of the bridge cannot be located far away from the slide-resistant pile and should be constructed on an inclined stratum. The distance between the pile foundation and the first row of the slide-resistant piles is only $2 \mathrm{~m}$. The pile cap platform has a size of $12.35 \mathrm{~m} \times 5.65 \mathrm{~m}$ and a height of $2.5 \mathrm{~m}$. A total of 8 $(4 \times 2)$ cast-in-place piles are built underneath the pile cap. Each bored pile has a diameter of $1.25 \mathrm{~m}$ and a height of around $36.5 \mathrm{~m}$.

The surface water of this project primarily is a relatively large and constant flow. The surface of the slope cannot generally accumulate rainwater. Instead, it primarily takes water from atmospheric precipitation and a small amount of crack water, both of which are discharged into the river. The water level in this river is about $2480 \mathrm{~m}$ above the sea level.

\section{Full-Scale Testing System}

Owing to the distinctive features of the described engineering project, the deformation of the slide-resistant piles is transferred to the foundation of the bridge and deforms it. In 
TABLE 1: Typical studies and the research gap.

\begin{tabular}{|c|c|c|c|}
\hline Authors & Types & Main findings & Research gap \\
\hline Ito and Matsui [5] & $\begin{array}{l}\text { Theoretical } \\
\text { analysis }\end{array}$ & $\begin{array}{l}\text { The theory of plastic deformation with the } \\
\text { condition of restrained pile top to estimate the } \\
\text { lateral force acting on stabilizing piles was } \\
\text { proposed. }\end{array}$ & $\begin{array}{l}\text { The studies focused on the stability of the slope, } \\
\text { while the deformation of the structure to be } \\
\text { protected (e.g., bridge structure on the slope) }\end{array}$ \\
\hline Poulos [7] & $\begin{array}{c}\text { Theoretical } \\
\text { analysis }\end{array}$ & $\begin{array}{l}\text { An approach for the design of piles to reinforce } \\
\text { slopes was proposed considering the sliding force. }\end{array}$ & has been overlooked. \\
\hline $\begin{array}{l}\text { Georgiadis } \\
\text { et al. [22] }\end{array}$ & $\begin{array}{l}\text { Theoretical } \\
\text { analysis }\end{array}$ & $\begin{array}{l}\text { Analytical equations were derived to determine } \\
\text { the undrained lateral bearing capacity of rigid } \\
\text { piles in cohesive soil. A critical nondimensional } \\
\text { distance between the pile and the crest of the slope } \\
\text { was proposed. }\end{array}$ & $\begin{array}{l}\text { The interaction between pile and soil was not } \\
\text { considered. }\end{array}$ \\
\hline $\begin{array}{l}\text { Kourkoulis } \\
\text { et al. [9] }\end{array}$ & $\begin{array}{l}\text { Numerical } \\
\text { simulation }\end{array}$ & $\begin{array}{l}\text { An example of dimensionless design charts was } \\
\text { presented for piles embedded in rock. Results } \\
\text { were presented for two characteristic slenderness } \\
\text { ratios and several pile spacing. }\end{array}$ & $\begin{array}{l}\text { A representative region of soil around the one } \\
\text { slide-resistant pile was considered instead of } \\
\text { modeling the whole system. }\end{array}$ \\
\hline
\end{tabular}

The load-carrying capacity for a prescribed displacement increases with an increase in the length to diameter ratio and undrained cohesion, whereas capacity reduces with increase in slope angle. The effect of sloping ground condition on

pile response was quantified by numerical analysis.
The interaction between pile and the bridge foundation was not considered.
Sawant [23]

Numerical simulation

A simple approximate pseudo-static method was used to estimate the maximum internal forces and horizontal displacements of pile groups in soil The full-scale field tests to verify the model were Elahi et al. [27]

Numerical simulation slopes. Simple modifications were applied to take into account the effect of slope on seismic deformations of the pile group, making use of the New-mark sliding block method.

The stabilizing piles in cohesive soil slopes during an earthquake had a significant effect on the Wang and Zhang [29]

Centrifuge model test reduction in the deformation of the slope, and this effect arrested the possible slip surface that would have occurred in an unreinforced slope.

A Menard pressure meter method and a selfboring pressure meter method were used to predict the $\mathrm{p}-\mathrm{y}$ reaction curves, which were then Frank and Pouget [12]

Field tests used in a numerical model to derive the overall pile behavior. The pile displacements and bending moments calculated by the numerical model were markedly overestimated.

New p-y curves for piles located on the crest of soft clay with different sloping ground surfaces under static lateral loading were developed. The effect of sloping angles on proposed $\mathrm{p}$-y curves was studied.

The test piles were loaded laterally using a hydraulic actuator. The proximity of the slope significantly affects the maximum lateral load Nimityongskul et al. [30] Full-scale tests capacity of the piles but not significantly when the piles are installed at $8 \mathrm{D}$ ( $\mathrm{D}$ is pile diameter) or greater from the slope crests. The effects of adjacent slopes to lateral behaviors of piles can be explained as a function of soil displacements.
Rathod et al. [17]

Scale model experiments
The load transfer between the slide-resistant piles and the bridge foundations was not researched.
The deformation transfer between the slidresistant pile and the bridge foundation was not considered.
The deformation transfer between the slidresistant pile and the bridge foundation was not considered.
The loading behavior of the pile foundations on inclined strata (in particular, the displacement transfer from the slide-resistant pile to the adjacent bridge piles) remains unexplored. this case, the traditional stability analysis of the slope cannot satisfy the project requirements. In order to analyze the stress characteristics of the bridge pile foundation on an inclined stratum, a full-scale loading test system has been constructed on the inclined stratum near the original site. The test system can also elucidate the mechanism of the 


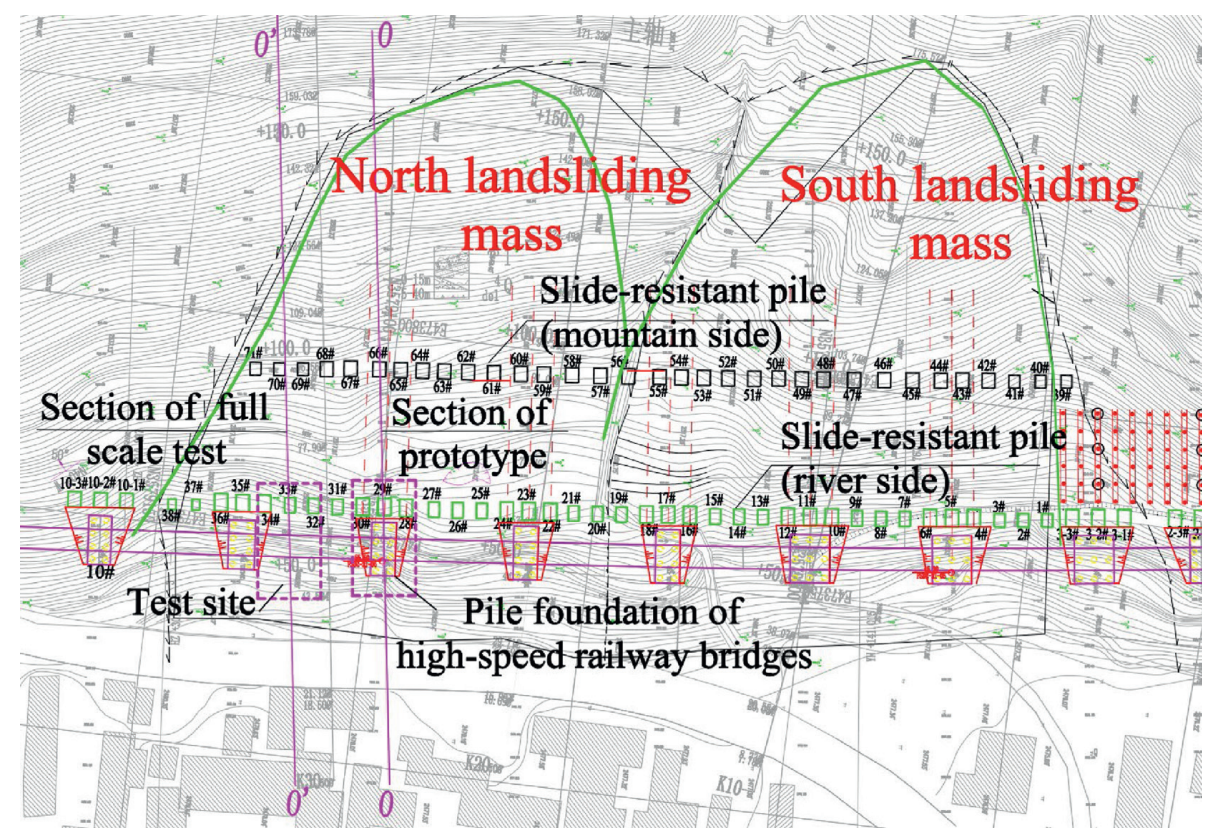

Figure 1: Positional relationship between the bridge and the landslide.

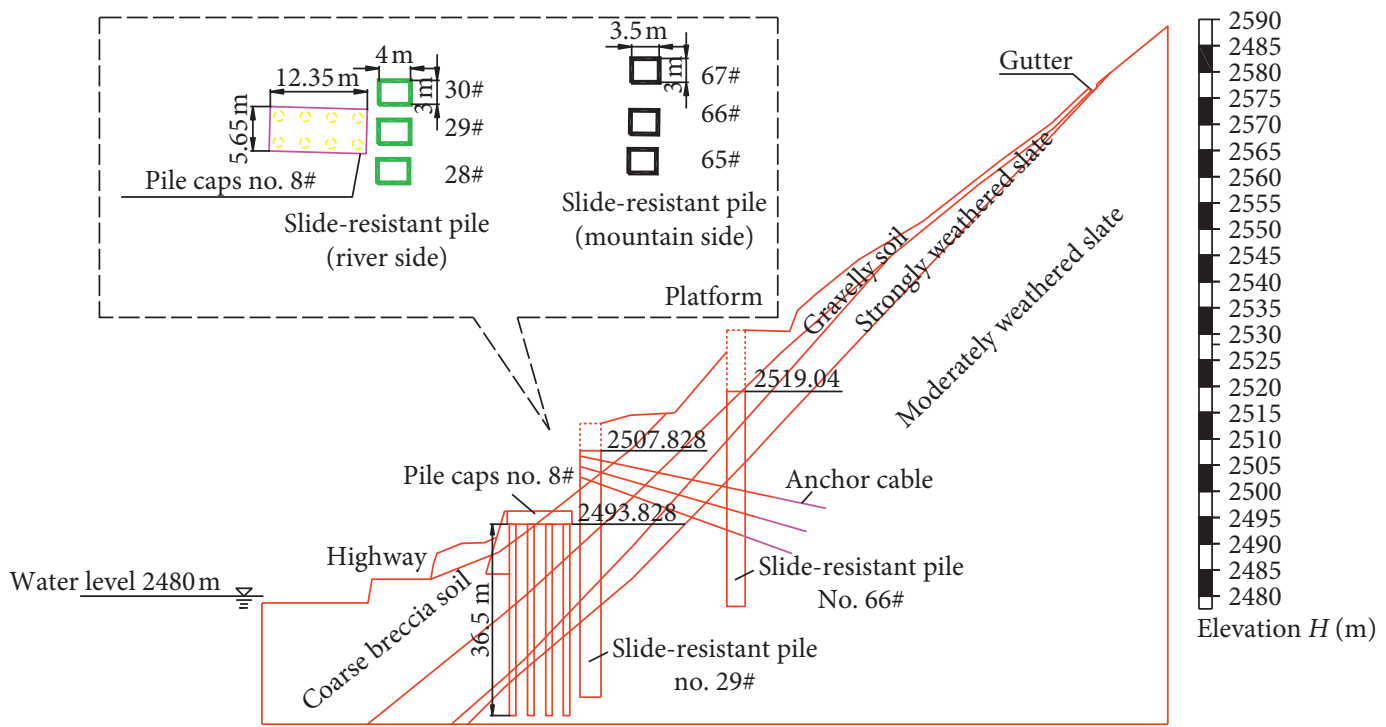

FIGURE 2: Stratum and structure of the prototype section.

TABle 2: Physical and mechanical parameters of the rock (soil).

\begin{tabular}{|c|c|c|c|c|c|}
\hline Rock (soil) material & $\begin{array}{c}\text { Specific weight } \gamma \\
\left(\mathrm{kN} / \mathrm{m}^{3}\right)\end{array}$ & $\begin{array}{c}\text { Elastic modulus } \\
(\mathrm{MPa})\end{array}$ & $\begin{array}{l}\text { Poisson's } \\
\text { ratio }\end{array}$ & $\begin{array}{l}\text { Cohesion } c \\
(\mathrm{kPa})\end{array}$ & $\begin{array}{c}\text { Angle of internal friction } \varphi \\
\left({ }^{\circ}\right)\end{array}$ \\
\hline Backfill soil & 20 & 23 & 0.2 & 25 & 30 \\
\hline Coarse breccia & 20 & 20 & 0.2 & 20 & 30 \\
\hline Gravelly soil & 21 & 40 & 0.2 & 25 & 30 \\
\hline Riprap rock & 22 & 250 & 0.2 & 30 & 35 \\
\hline $\begin{array}{l}\text { Strongly weathered slate } \\
\text { (phyllite) }\end{array}$ & 24 & 500 & 0.18 & 50 & 40 \\
\hline $\begin{array}{l}\text { Moderately weathered slate } \\
\text { (phyllite) }\end{array}$ & 25 & 1000 & 0.17 & 200 & 45 \\
\hline
\end{tabular}


deformation transfer from the slide-resistant piles to the bridge foundation.

3.1. Testing Site. The testing section is an on-site section used for performing full-scale field tests. It is selected to match the prototype section as much as possible. The following criteria are considered when selecting a target section:

(1) The lithology of the stratum should be as close to the prototype section (the $\mathrm{O}-\mathrm{O}$ section in Figure 1) as possible. Performing the test near the prototype section will yield the best testing characteristics.

(2) Because this project is currently under construction, limited space is available for the selection of the target section. Therefore, a full-scale test site should be selected to minimize the mutual effects of the field test and construction work.

According to the actual on-site conditions, the $\mathrm{O}^{\prime}-\mathrm{O}^{\prime}$ section depicted in Figure 1 has been finally selected as our testing section (its actual photograph is shown in Figure 3). This testing site is located in front of the 33\# slide-resistant pile, and its stratigraphic characteristics are most similar to those of the prototype section containing two rows of slideresistant piles. Here, 33\# is the first row of the slide-resistant piles with a length of $42 \mathrm{~m}$ and cross section size of $3.5 \mathrm{~m} \times 2.5 \mathrm{~m}$. The second row of the slide-resistant piles is 70\# with a length of $33 \mathrm{~m}$ and a cross section size of $3.0 \mathrm{~m} \times 2.5 \mathrm{~m}$.

3.2. Design of the Testing System. The testing platform is designed according to the following principles. The cast-inplace piles, pile caps, and loading walls are constructed first. Afterwards, the slide-resistant pile 33\# is used as the reaction wall, and the loading wall is pushed towards the top of the riverside. During this process, the loading wall deforms and transfers the deformation to the pile foundation and pile cap of the bridge. In this way, we can analyze the stress and deformation characteristics of the bridge pile foundation by measuring the displacement of the structures, surface displacement, deep displacement, and bending moment of the foundation. The field test platform consists of three parts including a full-scale test structure of the pile group, a largetonnage servo Jack load system, and a multifunctional measurement system.

3.2.1. Full-Scale Test Structure of the Pile Group. A total of 8 $(4 \times 2)$ newly bored piles with a diameter of $1.25 \mathrm{~m}$ and foundation lengths of $17.2-21.7 \mathrm{~m}$ were used in the test section. After finishing the construction of the pile foundation, a pile cap with a size of $12.35 \mathrm{~m}$ (length) $\times 5.65 \mathrm{~m}$ (width) $\times 2.5 \mathrm{~m}$ (height) was added to its top. The sizes and arrangements of the pile foundation and pile cap used in the prototype structure were identical. Furthermore, the strengths of the concrete and reinforcing bars were also the same. Therefore, the testing structure resembles the actual project site to the maximum extent.
3.2.2. Servo Jack Load System. The servo Jack load system includes a loading slot, a Jack, and a loading wall. The $1.4 \mathrm{~m}$ wide loading slot with five rows of jacks is oriented along the vertical direction. Each row contains nine jacks arranged in the horizontal direction and is controlled by a PLC servo loading system. One Jack can provide a maximum thrust of $1500 \mathrm{kN}$ and is equipped with multiple sensors to monitor its loading displacement and loading rate.

The spacing between the loading wall and the first row of the slide-resistant piles is $2.0 \mathrm{~m}$. The corresponding gap is filled with backfilling soil.

The dimensions of various structures in the prototype and test sections are listed in Table 3. As their values are nearly identical, the results obtained for the test section reflect the force and deformation parameters of the prototype section. The planar and vertical layouts of the fullscale field testing platform are shown in Figure 4.

3.2.3. Multifunction Measurement System. The tests performed in this study include measurements of the structure displacements, surface displacements, deep displacements, and generated stresses. During the loading process, the stress and deformation parameters of the test structure and surrounding rock (soil) are tracked instantaneously.

(1) Measuring the Displacements of the Structures. The measurements of the structure displacements during the full-scale field test include two components: (1) measuring the displacement at the top of the loading wall and (2) measuring the displacement at the top of the pile foundation.

(2) Measuring the Surface Displacement. The surrounding of the test platform is divided into two areas used for monitoring surface displacements: (1) the backfill area between the pile cap and the loading wall and (2) the surface area between the pile cap and the national road. During the test, displacements are measured at several monitoring points on the surface using total stations.

(3) Measuring the Displacement at the Top of the Jack. The PLC loading system of the Jack is equipped with a monitoring function to capture the loading displacement and loading rate. During the test, a dial indicator is used to measure the displacement at the top of the Jack.

(4) Measuring the Deep Displacement. The deep displacement is monitored by dividing the surrounding of the test platform into four regions: (1) the rock and soil between the loading wall and the pile cap; (2) the rock and soil beneath the bottom surface of the bridge's pile cap; (3) inside the pile foundation of the bridge; and (4) the rock and soil between the pile cap and the riverside. During the construction of the platform, inclinometers are buried at the target locations.

(5) Stress-Strain Test. To measure the stress generated in the bored pile during the loading process, rebar strain meters are placed on the vertical principal 


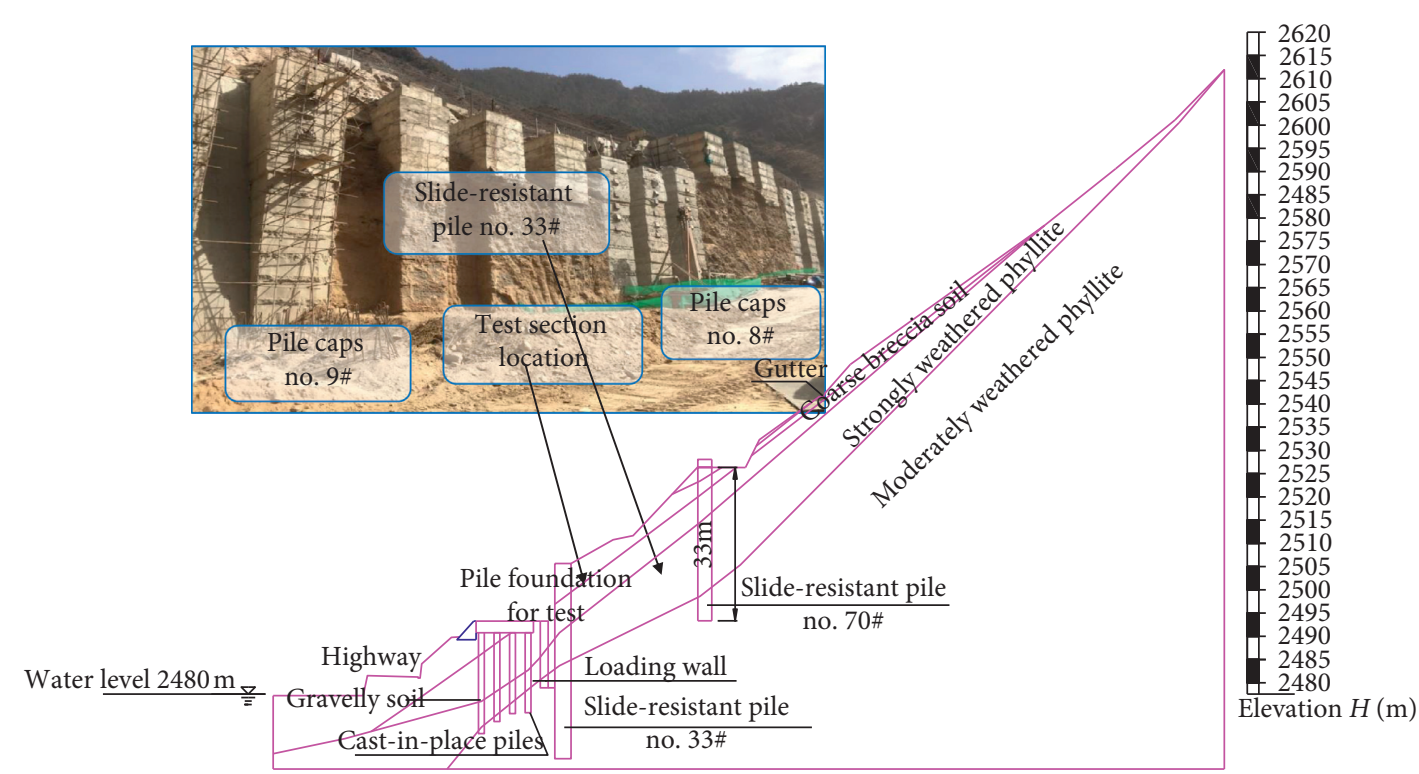

Figure 3: Stratum and structure of the test section.

TABLE 3: Dimensions of various structures located in the prototype and test sections.

\begin{tabular}{|c|c|c|c|c|c|c|c|}
\hline & \multicolumn{2}{|c|}{ Slide-resistant pile (first row) } & \multicolumn{2}{|c|}{ Slide-resistant pile (second row) } & \multicolumn{3}{|c|}{ Bridge foundation } \\
\hline & $\begin{array}{l}\text { Pile length } \\
\text { (m) }\end{array}$ & $\begin{array}{l}\text { Cross section size } \\
\quad(\mathrm{m} \times \mathrm{m})\end{array}$ & $\begin{array}{l}\text { Pile length } \\
\text { (m) }\end{array}$ & $\begin{array}{l}\text { Cross section size } \\
\qquad(\mathrm{m} \times \mathrm{m})\end{array}$ & $\begin{array}{l}\text { Pile length } \\
\text { (m) }\end{array}$ & $\begin{array}{l}\text { Pile diameter } \\
(\mathrm{m})\end{array}$ & $\begin{array}{l}\text { Size of the pile cap } \\
(\mathrm{m} \times \mathrm{m} \times \mathrm{m})\end{array}$ \\
\hline $\begin{array}{l}\text { Prototype } \\
\text { section }\end{array}$ & 47 & $4 \times 3$ & 41 & $3.5 \times 3$ & 36.5 & 1.25 & $12.35 \times 5.65 \times 2.5$ \\
\hline Test section & 42 & $3.5 \times 2.5$ & 33 & $3 \times 2.5$ & $\begin{array}{c}17.2 / 17.4 / \\
19.1 / 21.7\end{array}$ & 1.25 & $12.35 \times 5.65 \times 2.5$ \\
\hline
\end{tabular}

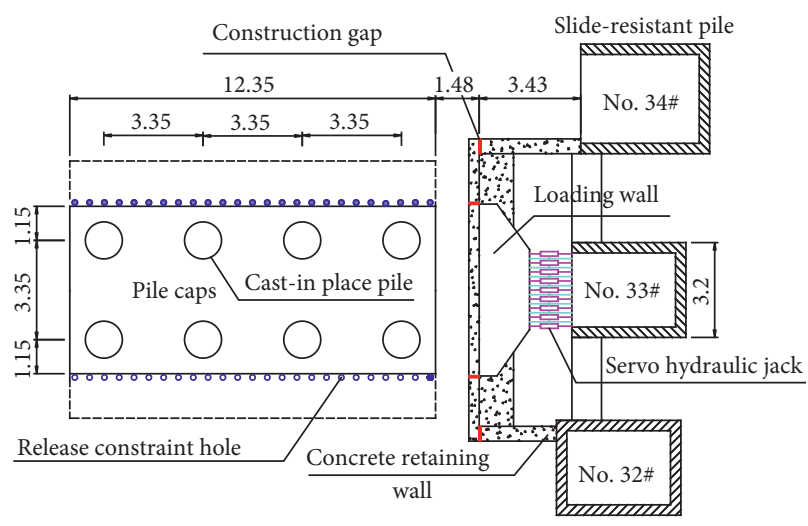

(a)

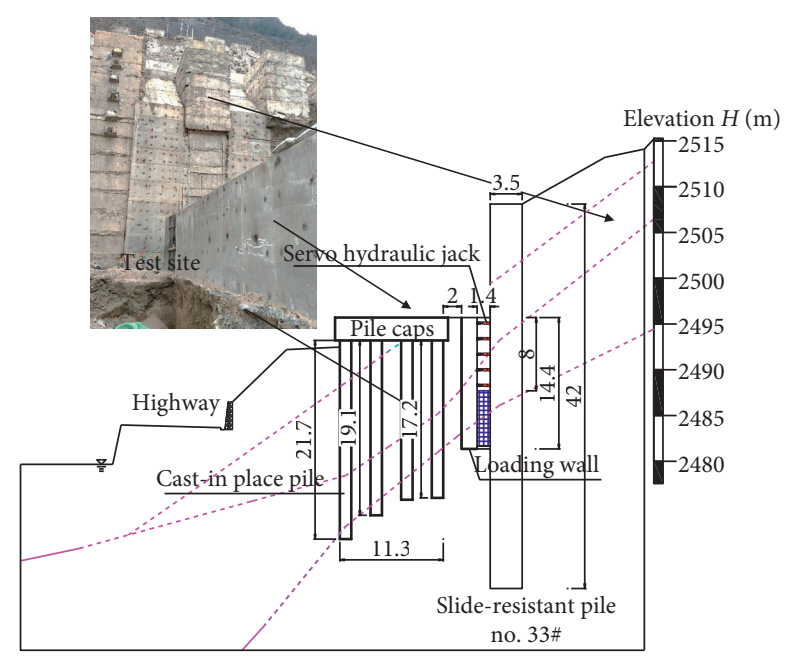

(b)

Figure 4: Plane layouts of the full-scale in situ testing platform (units: $\mathrm{cm}$ ). (a) Platform. (b) Elevation.

reinforcement of the cast in situ pile during the construction of the test platform. The arrangement of the testing points in the utilized model is shown in Figure 5.
3.3. Loading Process. Taking the top of the loading wall as the reference, five rows of jacks have been arranged from the top to the bottom. The distances between the installation depths of the jacks and the top of the loading wall are 0.60, 2.30, 


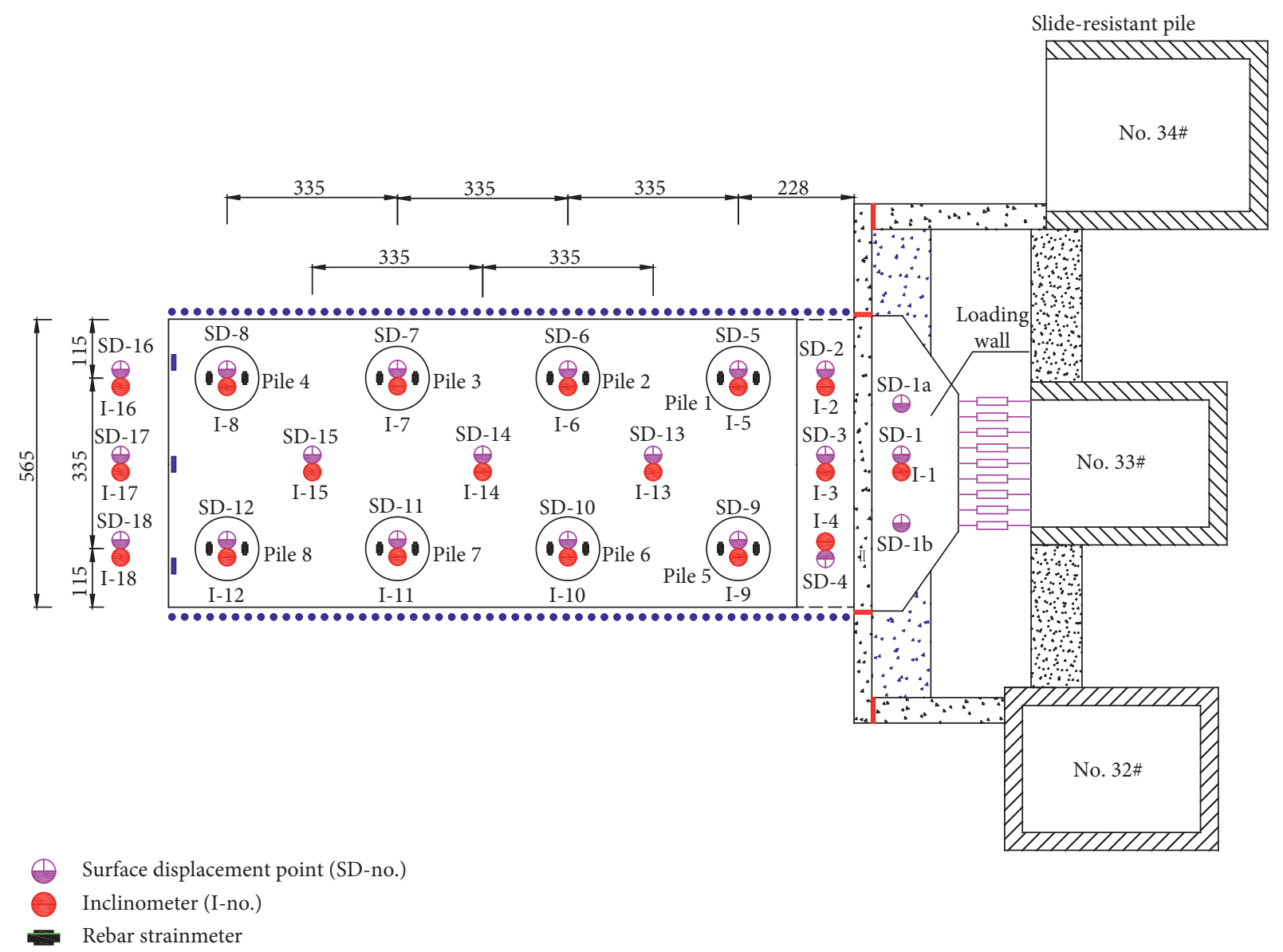

FIgURE 5: Plane layout of the measuring points.

$4.00,5.70$, and $7.40 \mathrm{~m}$. The displacements of different rows of jacks under various loading conditions are listed in Table 4.

3.4. Analysis of Test Results. During the test, the displacement generated by the loading wall is transferred to the structure of the bridge, soil under the pile cap, and soil near the riverside, which causes deformation and generates internal stress in the bridge structure. In the data analysis, the displacements of the bridge structure, soil, and loading wall are compared using the displacement of the loading wall as the reference. The mechanism of the displacement transfer from the loading wall is elucidated. Based on the obtained results, the internal stress generated in the bridge pile foundation is determined.

Figure 6 shows the horizontal displacements of the loading wall measured under different loading conditions. Their values obtained for the top of the loading wall are 2.7, $5.2,8.7,11.8$, and $15.0 \mathrm{~mm}$, indicating that increasing the load causes the loading wall to tilt at a higher inclination angle. Meanwhile, the deformation of the wall itself is almost linear with a slight deflection, suggesting its relatively large degree of stiffness.
3.4.1. Ground Surface and Pile Group Movement. SD-2, SD3 , and SD-4 are the points used to measure the surface displacements of the soil between the loading wall and the pile cap. Figure 7 displays the relationship between the displacements at these three points and that at the top of the loading wall. It shows that the surface displacement of the soil between the loading wall and the pile cap increases almost linearly with increasing displacement of the loading wall at a ratio of approximately 0.70 . The displacement of the loading wall increases faster than that of the soil, which is caused by both the spreading of the stress generated by the loading wall and the compression of the soil itself.

SD-5, SD-6, SD-7, and SD- 8 are the locations, at which the displacements of the caps for piles 1-4 are measured, while SD-9, SD-10, SD-11, and SD-12 are the measurement points corresponding to piles 5-8. Figure 8 displays the relationships between the displacement of the cap top and the displacement at the top of the loading wall. It shows that different pile caps exhibit similar horizontal displacement patterns. For piles 1-8, the displacements of the pile caps increase almost linearly with increasing displacement of the loading wall. During the later stage of the loading process, the rate of increase decreases. In theory, the displacements of 
TABLE 4: Displacements of jacks under different loads.

\begin{tabular}{|c|c|c|c|c|c|c|}
\hline \multirow{2}{*}{ Jack row number } & \multirow{2}{*}{ Location (m) } & \multicolumn{5}{|c|}{ Jack displacement (mm) } \\
\hline & & Load 1 & Load 2 & Load 3 & Load 4 & Load 5 \\
\hline 1 & -0.6 & 1.1 & 3.1 & 5.6 & 9.9 & 11.2 \\
\hline 2 & -2.3 & 1.0 & 3.0 & 5.5 & 9.1 & 10.2 \\
\hline 3 & -4.0 & 0.9 & 2.9 & 4.9 & 8.0 & 9.1 \\
\hline 4 & -5.7 & 0.7 & 2.7 & 4.2 & 7.0 & 8.0 \\
\hline 5 & -7.4 & 0.6 & 2.1 & 3.6 & 6.2 & 7.0 \\
\hline
\end{tabular}

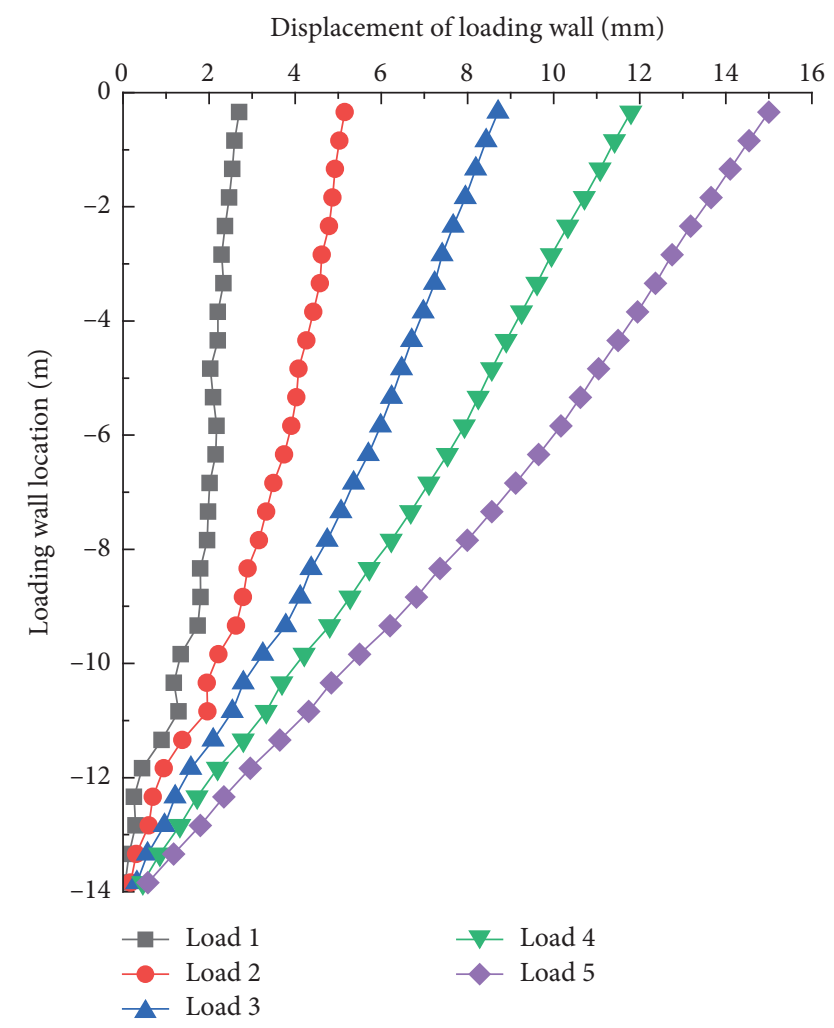

FIgURE 6: Displacements of the loading wall at various loading steps.

different measuring points on the top of the pile cap should be consistent. However, slight differences between their values are observed experimentally due to the deformation of the pile cap and measurement errors. In general, for $90 \%$ of the measuring points, the horizontal displacement ratio between the top of the pile cap and the top of the loading wall ranges between 0.56 and 0.90 with an average value of 0.73 .

For this engineering project, the calculated extreme horizontal displacement of the pile cap is $15.54 \mathrm{~mm}$ according to the "Design Specifications of Railway Bridges and Culverts" (TB10002-2017). Based on the results of the field test, the maximum displacement of the slide-resistant pile during landslide must be smaller than $22.2 \mathrm{~mm}$. It can ensure that the displacement of the bridge pile cap remains below the threshold value. However, control over the deformation of the slide-resistant pile is often neglected during its design. In this case, pile deformation may affect the operation of the bridge structure under extreme conditions.

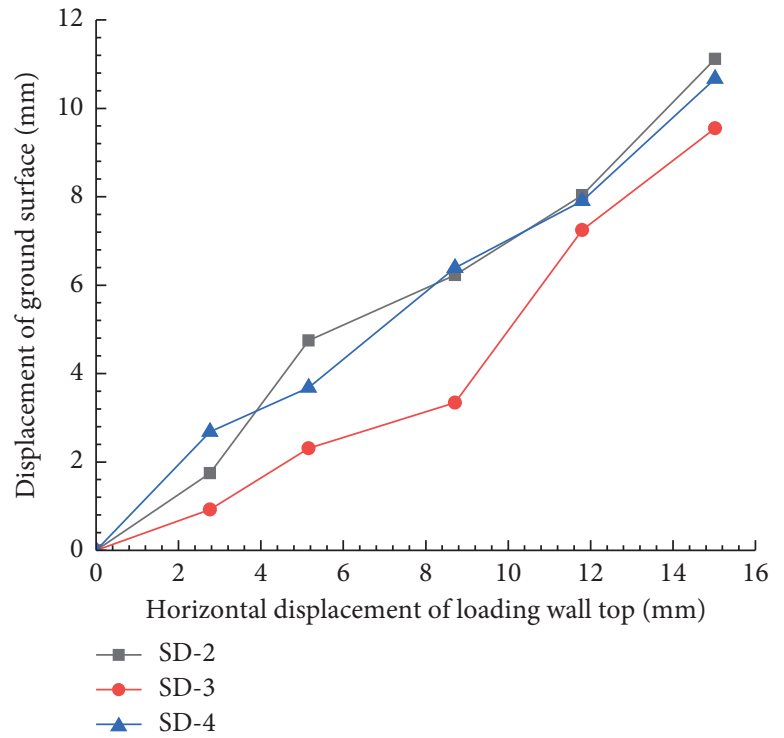

Figure 7: Relationship between the displacements of the loading wall and the soil located between the loading wall and the cap.

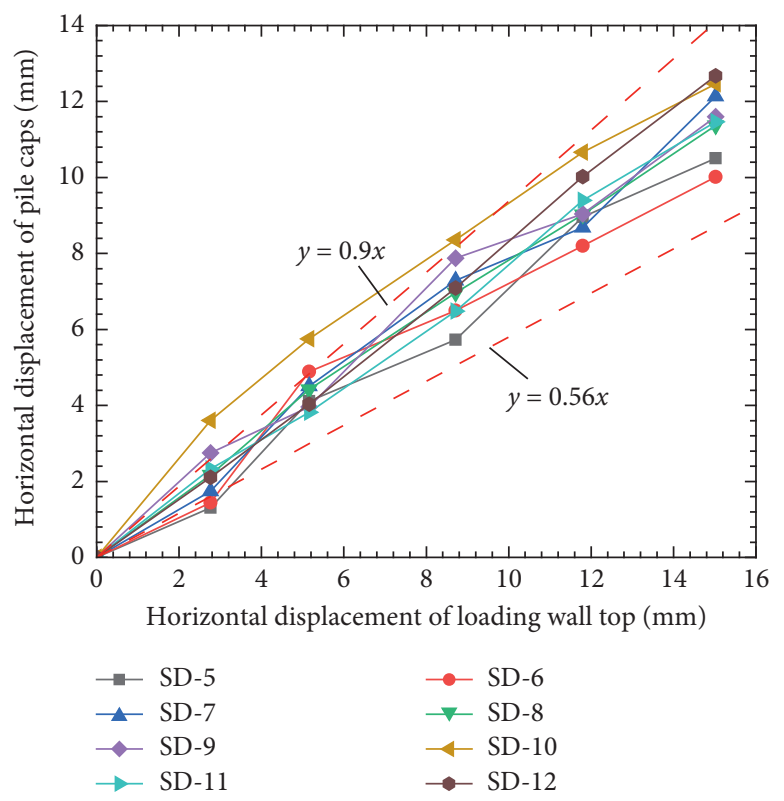

FIGURE 8: Relationships between the displacements at the top of the loading wall and different pile caps. 
SD-16, SD-17, and SD-18 are the locations for measuring the soil displacement at the riverside of the cap. Figure 9 displays the relationships between the displacements of the soil at the riverside of the cap and top of the loading wall. It shows that the former parameters increase linearly with increasing displacement of the loading wall. This is because the soil at the riverside of the cap is close to the free surface of the local slope. The displacement ratio between these two values is around 0.58 .

3.4.2. Subsurface Movement Analysis. I-2, I-3, and I-4 are the points, at which deep displacements of the soil between the loading wall and the pile cap are measured. Figure 10 displays the distributions of the deep displacements obtained for measuring point I-3 under different loading conditions. As shown in this figure, the horizontal displacement of the deep soil increases nonlinearly with increasing displacement of the loading wall. The maximum horizontal displacement of the stratum occurs at a depth of $3.0 \mathrm{~m}$ beneath the surface. The apparent deep displacement of the soil occurs at a depth of $14 \mathrm{~m}$. It corresponds to the height of the loading wall.

Figure 11 depicts the distributions of the horizontal displacements of pile 1 obtained under different loading conditions. It shows that the horizontal displacement of the pile increases gradually with increasing displacement of the loading wall. Owing to the fixing effect of the pile cap, the horizontal displacement remains constant within $2.5 \mathrm{~m}$ beneath the top surface of the pile cap. The horizontal displacement of the pile body is significant at depths below $14 \mathrm{~m}$. The displacement pattern of each pile body remains almost the same at different loading steps. Therefore, the same conclusions were made regarding the other piles without conducting actual experiments.

I-13, I-14, and I-15 are the deep displacement measuring points located in the middle of the pile cap. Among these points, I-13 is closer to the mountainside, while measuring point I-15 is closer to the riverside. Figure 12 displays the testing results obtained at loading step 5 . It shows that different measuring points exhibit almost identical patterns of the deep horizontal displacement in the soil. The displacements of the soil near the riverside (measuring point I-15) are larger than those measured at I-13 and I-14. This is because the pile cap is constructed on an inclined stratum and adjacent to the free surface of the slope. In this case, the deformation of the soil (especially near the free surface) is further triggered by the inclined stratum in addition to the impact of the loading wall.

Figure 12 also compares the horizontal displacement of the loading wall (measuring point I-1) and that of the soil between the loading wall and the pile cap (measuring point I-3). From the obtained results, the following conclusions can be made:

(1) At deep locations, the horizontal displacements of the loading wall and the soil before the loading wall exhibit almost linear distributions with very close magnitudes. The horizontal displacement of the soil within the height range of the pile cap remains almost unchanged at different depths. The horizontal displacement of the soil is smaller than that of the loading wall due to the blockage effect.

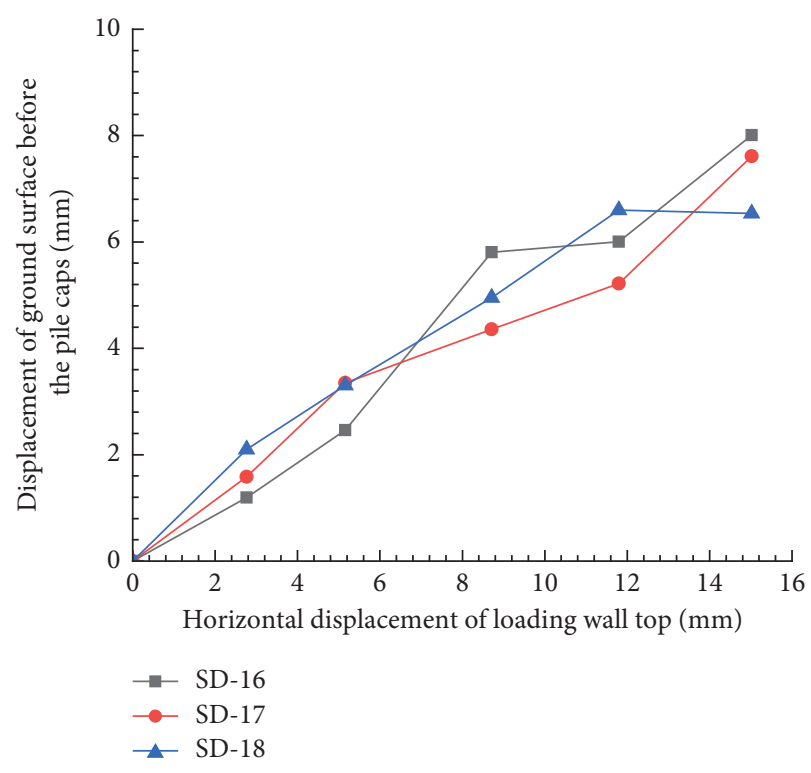

FIGURE 9: Relationships between the displacements of the loading wall and the soil located at the riverside of the cap.

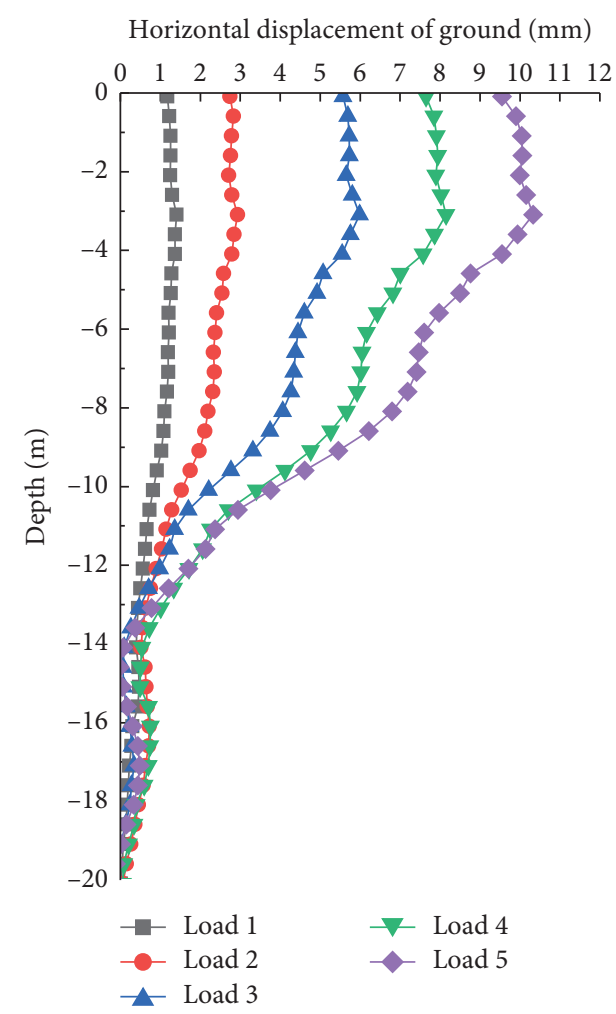

FIgURE 10: Displacements of the soil between the loading wall and the cap measured at various loading steps.

(2) The horizontal displacements of the soil under the pile cap are smaller than the horizontal displacement of the loading wall. The horizontal displacement of the deep stratum increases gradually from the mountainside to the riverside (between measuring points I-13 and I-15). Even for shallow soil, the 


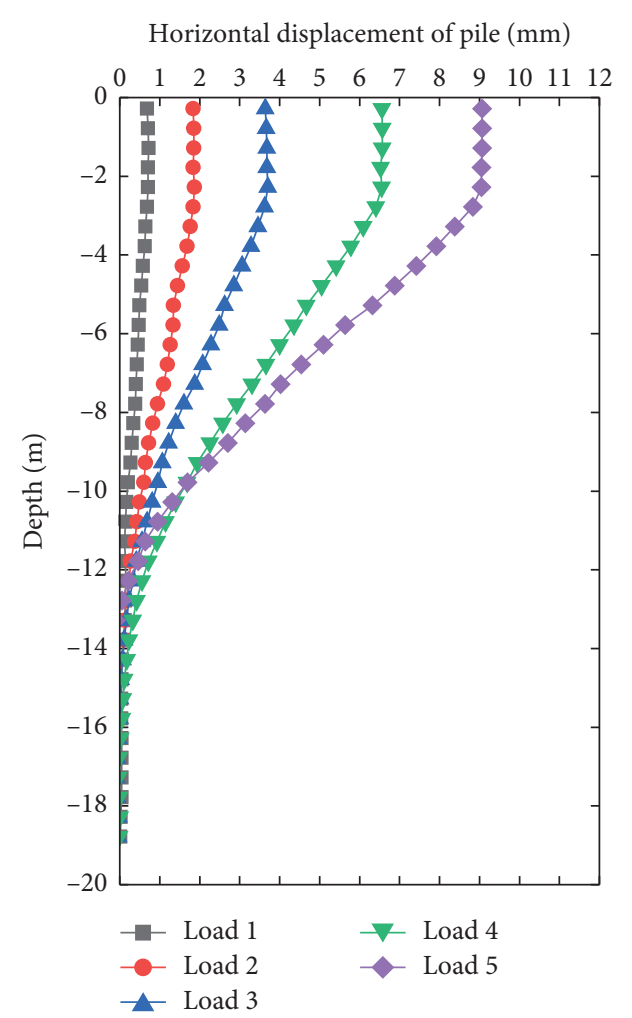

Figure 11: Displacements of pile 1 measured at various loading steps.

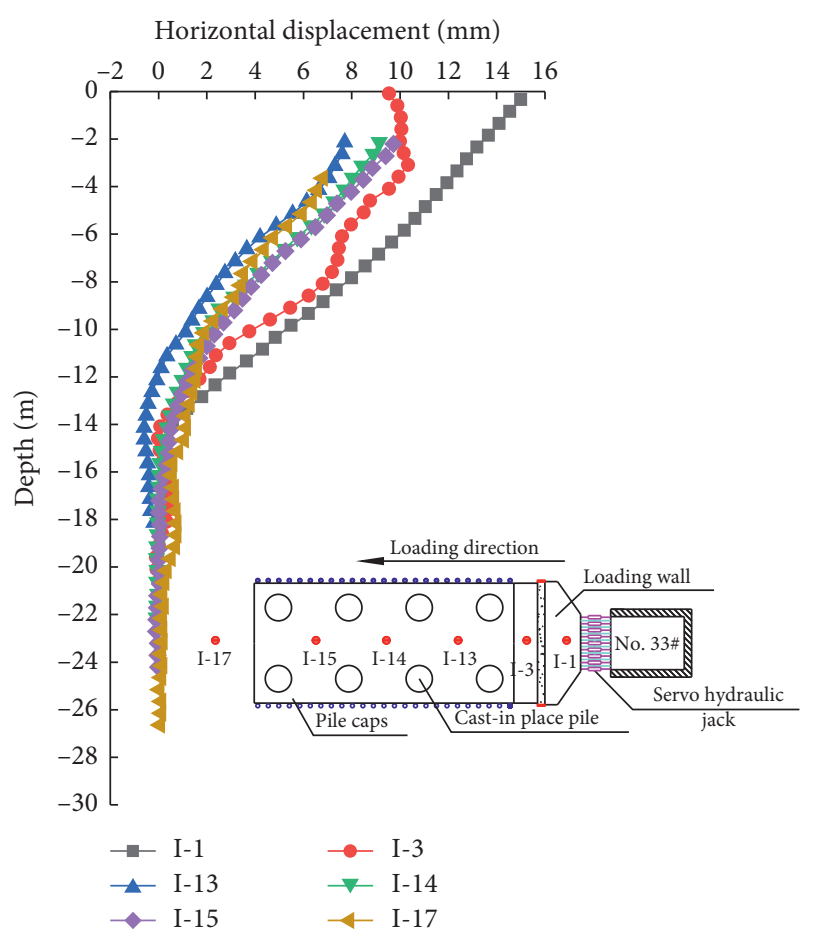

FIGURE 12: Regularity of the displacement transfer between the loading wall and the soil. displacement of the stratum at $\mathrm{I}-15$ is greater than that at measuring point I-13. From these findings, it can be inferred that under the greater loading, the horizontal displacement of the pile cap close to the riverside may exceed the horizontal displacement of the loading wall. In this case, the testing section is subjected to a landslide risk.

Figure 13 compares the horizontal displacements of the loading wall (measuring point I-1), soil between the loading wall and the pile cap (measuring point I-3), and piles (measuring points I-9-I-12) determined at loading step 5. The horizontal displacement of the pile foundation exhibits a trend similar to that observed for the horizontal displacement of measuring point I-3. However, the displacement of the pile foundation is consistently smaller than the displacement of the soil. In contrast to the loading wall, the pile foundation demonstrates flexible deformation characteristics, and a significant reverse bend is observed on the pile body.

3.4.3. Internal Force Analysis. Figure 14 shows the bending moments of piles 1-4 measured at different loading steps. From these data, the following conclusions have been drawn:

(1) The maximum bending moment of the bridge pile foundation is usually observed at the top of the bridge pile and at the embedded end of the pile foundation during each loading. Therefore, the horizontal flexural capacity of the pile body should be re-checked during the design process.

(2) For piles 1-4 (mountainside-riverside), the bending mode remains basically the same where an inflection point located $5-10 \mathrm{~m}$ below the pile top is detected. The location of this point gradually moves downward from pile 1 to pile 4 .

(3) The bending moment is reduced gradually from pile 1 to pile 4 because an increasing fraction of the landslide thrust is consumed by the pile body. As shown by the experimental data, the value of the bending moment at the pile top decreases slightly from pile 1 to pile 3 , and the magnitude obtained for pile 4 is much smaller than the other three values. In general, the bending moment at the top of pile 4 is reduced by around $20 \%$. Therefore, when designing bridge piles, special attention should be paid to the design features that enhance the horizontal flexural resistance of the pile along the landslide direction.

\section{Numerical Analysis Model and Its Verification}

4.1. Numerical Analysis Model. In this study, we developed a refined finite difference numerical model that incorporates the high and steep slope, slide-resistant piles, and bridge structures. 


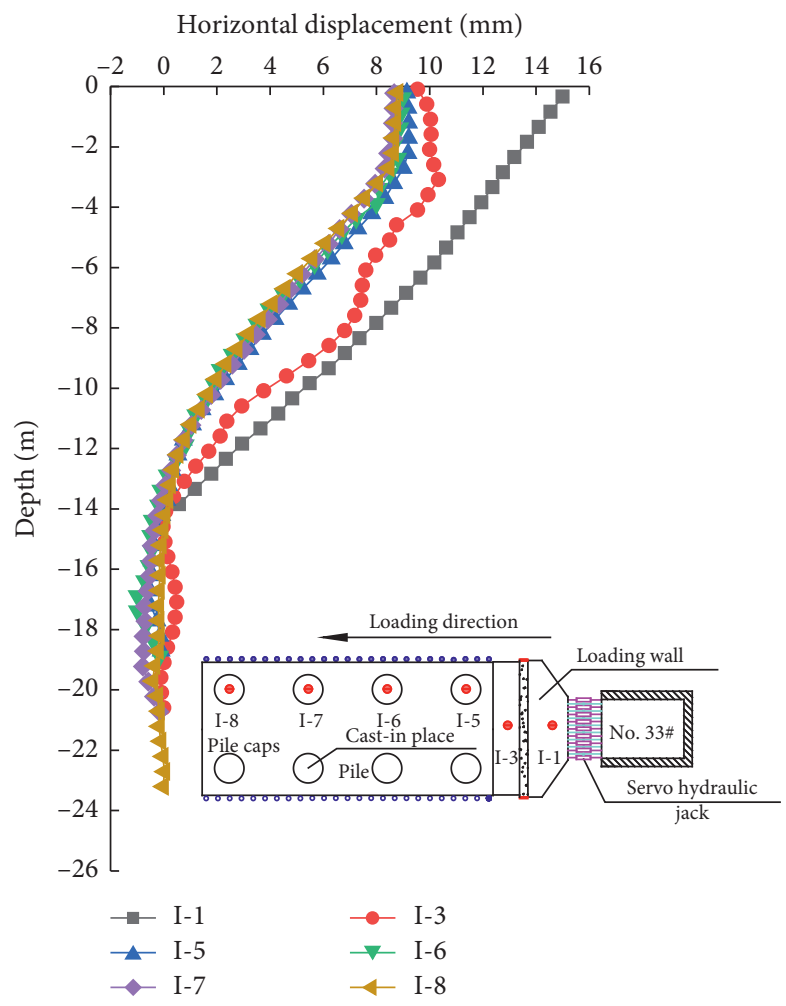

Figure 13: Regular patterns of the displacement transfer between the loading wall and the pile.

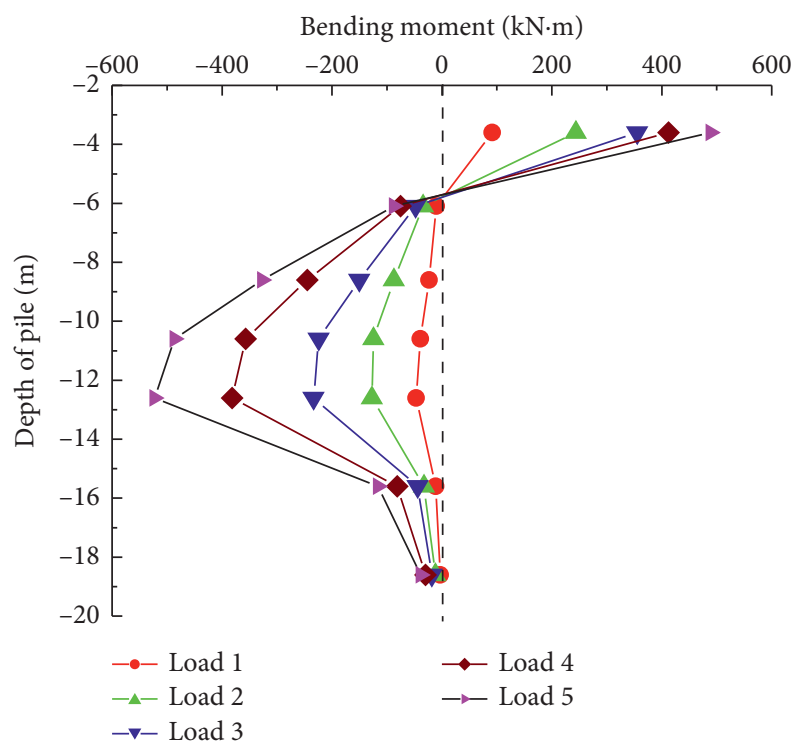

(a)

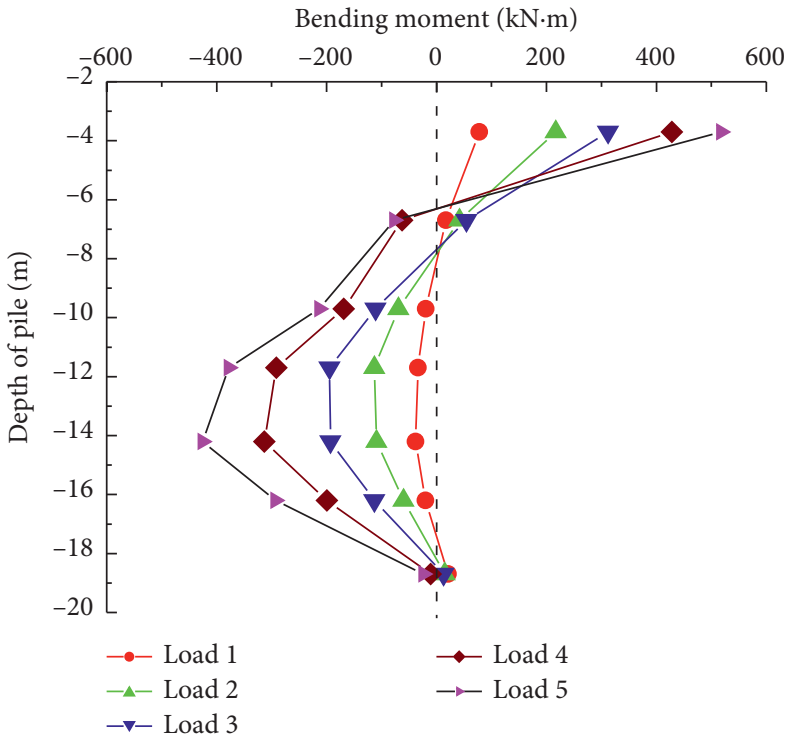

(b)

Figure 14: Continued. 


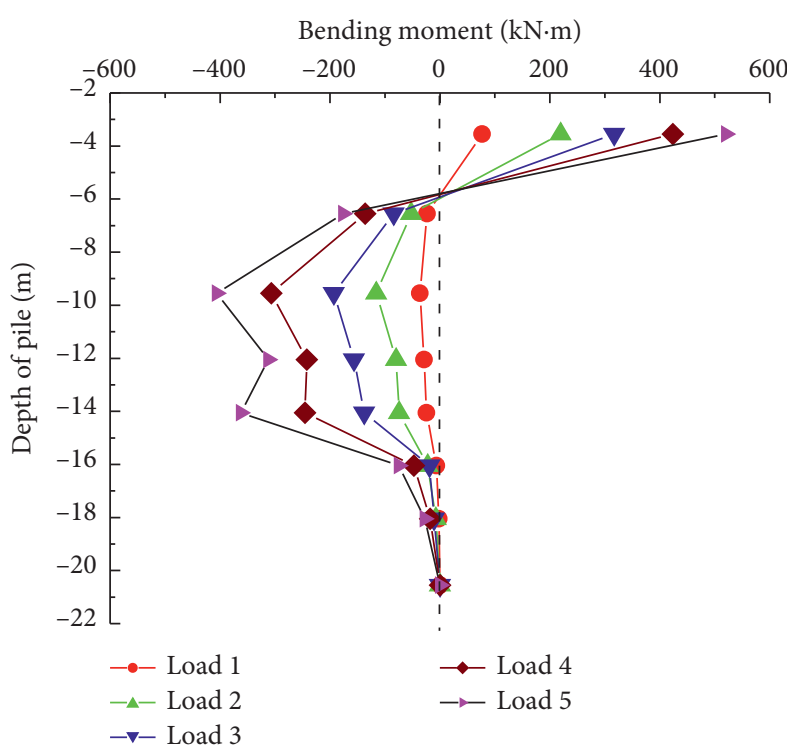

(c)

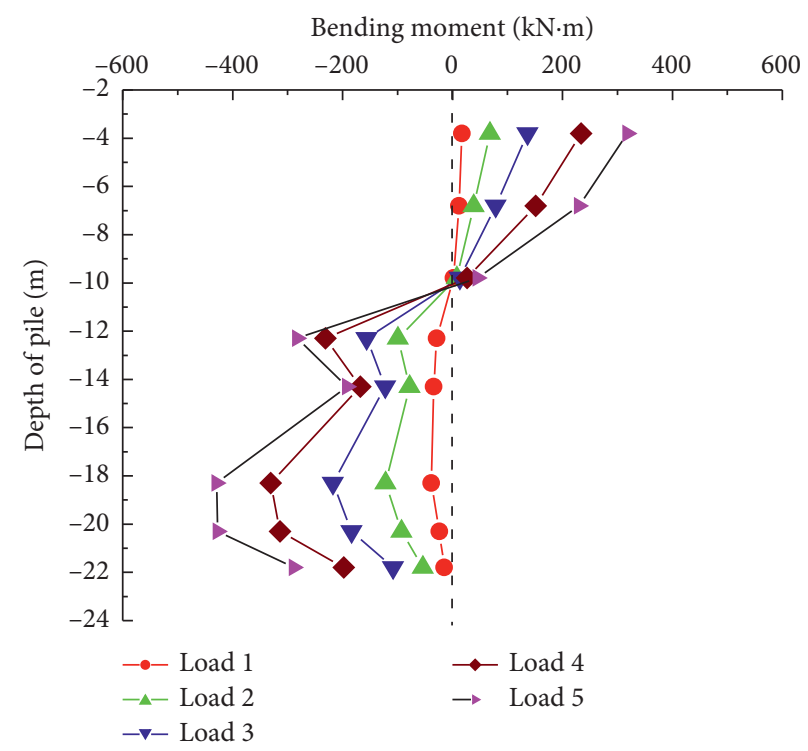

(d)

Figure 14: Bending moments of piles 1-4 measured at different loading steps. (a) Pile 1. (b) Pile 2. (c) Pile 3. (d) Pile 4.

An explicit finite difference program (FLAC3D) was used to establish the numerical model. In the model, the motion of an elementary volume of the medium from the forces applied to it is governed by

$$
\sigma_{i j, j}+\rho b_{i}=\rho \frac{\mathrm{d} v_{i}}{\mathrm{~d} t}
$$

where $\rho$ is the mass-per-unit volume of the medium, $b$ is the body force per unit mass, $\sigma_{i j}$ is symmetric stress tensor, and $(\mathrm{d} v / \mathrm{d} t)$ is the material derivative of the velocity.

The foundation to the nodal formulation of the equations of motion is derived from finite difference formulation of the strain-rate tensor components for the tetrahedron as

$$
\int_{v} v_{i, j} \mathrm{~d} V=\int_{s} v_{i} n_{j} \mathrm{~d} S
$$

where the integrals have taken over the volume $V$ and the surface $S$ of the tetrahedron, respectively, and $n$ is the exterior unit vector normal to the surface. The mathematical illustration is described in greater detail in the work of Cundall [32].

In the model, the rock mass, soil body, and slide-resistant pile are simulated by solid elements; the anchor is simulated by an anchor cable unit; and the Mohr-Coulomb constitutive model is used to describe the soil and rock. The anchor cable unit is a two-node linear unit, which allows only axial deformation and possesses one degree of freedom in the translational direction. A one-dimensional constitutive model is adequate for describing the axial behavior of the anchor. The axial stiffness, $K$, is determined based on the reinforcement cross-sectional area, $A$, Young's modulus, $E$, and element length, $L$, by the relation:

$$
K=\frac{A E}{L}
$$

A tensile- and compressive-yield strength, $F_{t}$ and $F_{c}$, may be assigned to the cable element such that cable forces that are greater than these limits cannot develop.

The grout annulus is assumed to behave as an elasticperfectly plastic solid. The shear force, $F^{t}$, is determined by

$$
F^{t}=k_{g} u^{t}
$$

where, $k_{g}$ is grout stuffiness, $u^{t}$ is relative shear displacement.

The pile cap is simulated by the shell structural units composed of 3-node equally thick triangles each. The pile foundation of the bridge is simulated by pile units. One such unit is a combination of a dual unit and an anchor cable unit, which can be used to simulate the interaction between the pile end and the soil. The shear behavior of the pile-grid interface is cohesive and frictional in nature. It is modeled in the same way as the grouted-cable system.

Computational analysis was performed using this model to further validate the results of experimental testing. Figure 15(a) shows the numerical analysis model utilized for the field test (described in Figure 3), while Figure 15(b) depicts the model established for the prototype section (see Figure 2). The parameters of the physical units used in the model are listed in Table 2, and the parameters of the structural units are presented in Tables 5 and 6.

Most of the previous studies focus on the stability of the slope. Therefore, their numerical model only considers slope and slide-resistant pile, and they have overlooked the deformation of the bridge foundation. In this study, fine-scale numerical models are built, and the slope, the slide-resistant 


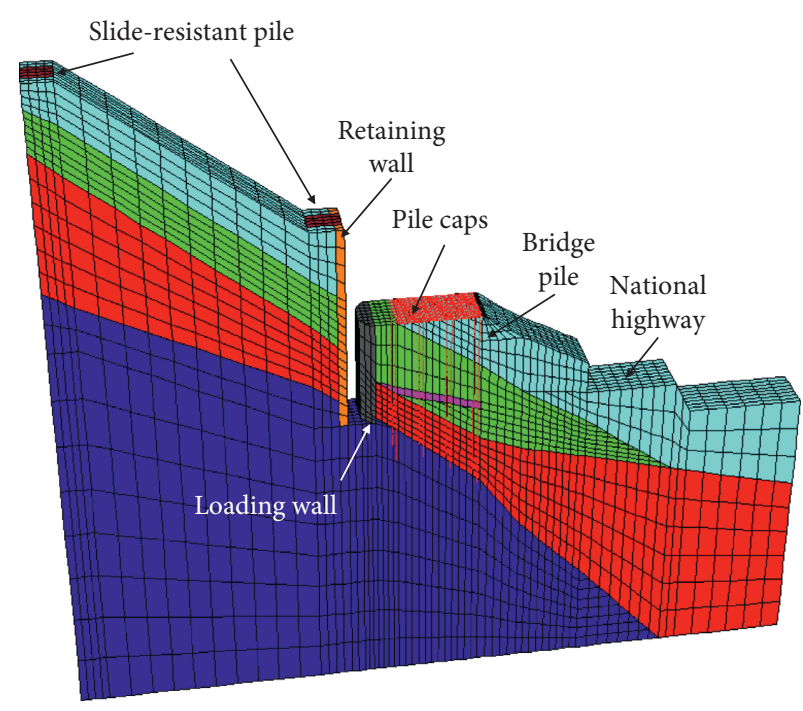

(a)

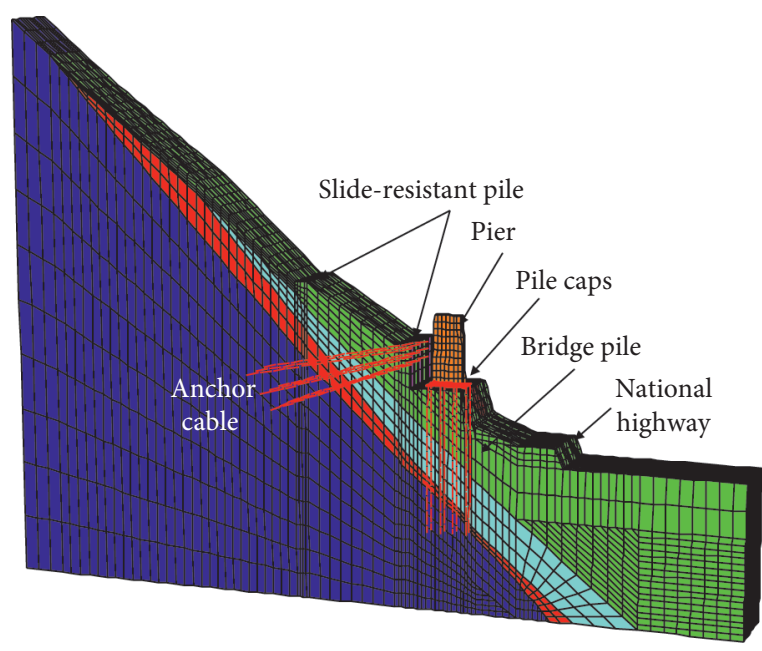

(b)

Figure 15: Numerical analysis models developed in this work. (a) Testing section. (b) Prototype section.

TABle 5: Parameters of the anchor cable units.

\begin{tabular}{lc}
\hline Parameter & Value \\
\hline Diameter of a single unit $(\mathrm{mm})$ & 0.0152 \\
Cross-sectional area $\left(\mathrm{m}^{2}\right)$ & $1.09 E-03$ \\
Elastic modulus $(\mathrm{Pa})$ & $2.00 E+11$ \\
Tensile strength $(\mathrm{N})$ & $2.03 E+06$ \\
Stiffness of the cement slurry $\left(\mathrm{N} / \mathrm{m}^{2}\right)$ & $7.00 E+06$ \\
Cohesion of the cement slurry $(\mathrm{N} / \mathrm{m})$ & $1.00 E+05$ \\
Diameter of the grout hole $(\mathrm{m})$ & $1.50 E-01$ \\
Outer circumference of the cement slurry $(\mathrm{m})$ & $4.71 E-01$ \\
\hline
\end{tabular}

TABle 6: Parameters of the pile units.

\begin{tabular}{lc}
\hline Parameter & Value \\
\hline Diameter of a single unit $(\mathrm{mm})$ & 1.25 \\
Cross-sectional area $\left(\mathrm{m}^{2}\right)$ & $1.23 E+00$ \\
Elastic modulus $(\mathrm{Pa})$ & $3.15 E+10$ \\
Outer circumference $(\mathrm{m})$ & 3.93 \\
Shear stiffness of the spring $\left(\mathrm{N} / \mathrm{m}^{2}\right)$ & $1.31 E+11$ \\
Shear cohesion per unit length $(\mathrm{N} / \mathrm{m})$ & $1.00 E+10$ \\
Normal stiffness of the spring $\left(\mathrm{N} / \mathrm{m}^{2}\right)$ & $1.30 E+00$ \\
Normal cohesion per unit length $(\mathrm{N} / \mathrm{m})$ & $1.00 E+04$ \\
\hline
\end{tabular}

pile, the bridge foundation, and the anchor cable are considered. In addition, large-scale field tests were conducted to verify the application of the numerical model.

4.2. Simulation Process. The primary purpose of the simulation of the testing section is a comparison of the theoretical data with the results of the in-situ field test. During simulation, the displacement of the loading wall is selected to match exactly the actual working conditions used in the field test. The transfer characteristics of the load and displacement during the process are analyzed. The parameters and simulation methods used in this study are further verified.
After the validation of the simulation parameters, a parametric study is performed on the prototype section using the numerical model. Specifically, a limit analysis approach is adopted in the numerical simulation of this section. In other words, the soil strength is first reduced continuously to identify the safety factor of the system. Afterwards, the strength coefficient of the soil is decreased to determine the internal stress and deformation of the bridge pile foundation at the system safety factor equal to 1 .

4.3. Verification of Simulation Parameters. The stratum's horizontal displacement simulated at loading step 5 is shown in Figure 16. These data are consistent with the horizontal displacement observed in the field test.

The displacement of the loading wall obtained via the numerical simulation is compared with that obtained during the field test in Figure 17. It is found that the theoretical and experimental deformation characteristics of the loading wall are almost identical (in particular, the corresponding degrees of inclination are very close). While certain deflections of the wall are observed during the field test, the result obtained by the numerical simulations is generally consistent.

Figure 18 shows the relationship between the experimental and calculated horizontal displacements of the pile cap and loading wall. The numerical simulation data are consistent with the measured parameters; however, the measured displacement ratio is greater than the calculated one. This difference is attributed to the disturbance of the soil in the actual project. In general, the horizontal displacement of the pile cap increases linearly with increasing displacement of the loading wall. The displacement transfer ratio from the slide-resistant pile to the pile cap of the bridge is around $70 \%$.

Figure 19 shows the horizontal displacements of the pile foundation calculated at loading step 4. Here, the 


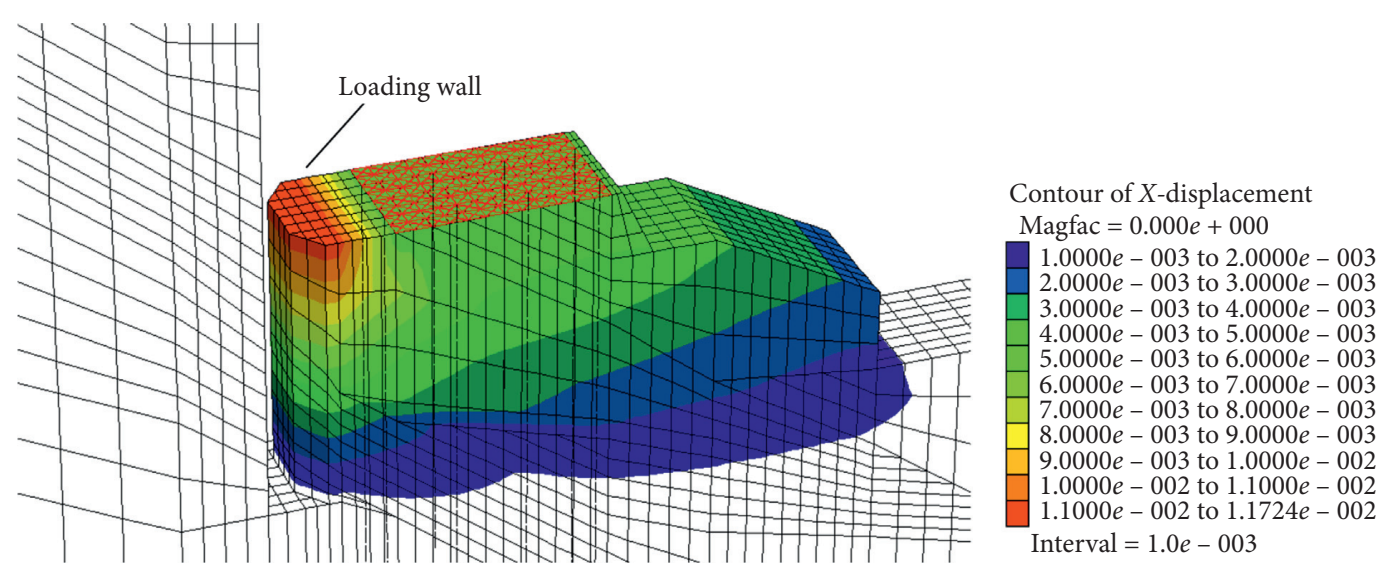

FIgURE 16: Contours of the horizontal displacement observed at loading step 5 (units: $\mathrm{m}$ ).

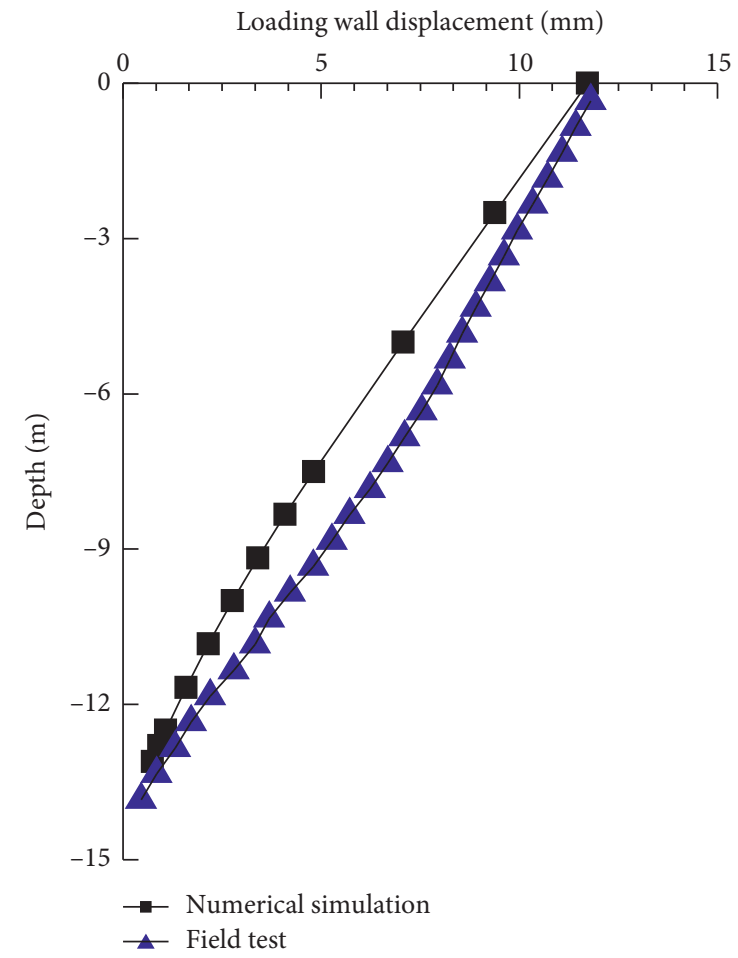

FIGURE 17: Displacements of the loading wall determined via the numerical simulation and during the field test.

displacement of the pile foundation along the transverse direction of the bridge follows the pattern that is almost identical for different positions. The deformation mode of the pile foundation observed in the field test is very similar to that determined by the numerical simulation. In particular, two deflection points are detected both experimentally and theoretically. The displacements at the pile top and pile body measured during the test are also equal to the calculated values. These consistencies further validated the reliability of the model and its parameters used in the numerical simulation.

The calculated bending moment of each pile body in the pile foundation is shown in Figure 20. The same pattern is

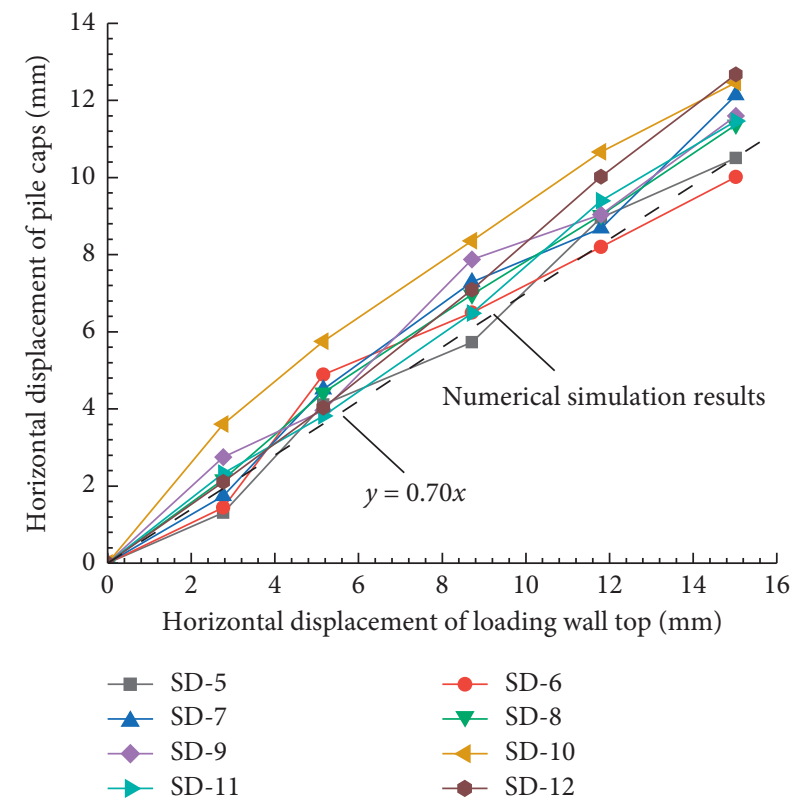

FIGURE 18: Experimental and calculated displacements of the cap and the loading wall.

observed for the results of the numerical simulation and field test. In both datasets, the maximum positive and negative bending moments are obtained for the top and middle-tolower part of the pile body. In addition, the magnitudes of the bending moments determined experimentally and theoretically are very close to each other.

\section{Numerical Simulation Analysis}

The working conditions of the bridge pile foundation on a high and steep slope can be very different from those of the same foundation on a planar stratum. On the one hand, the lower part of the bridge pile is embedded into the rock layer, which helps it to resist landslide and improve the slope stability. On the other hand, the pile foundation of the bridge is subjected to an inclined load under normal operation conditions; as a result, the stress and deformation of the pile are affected by various factors including the pile stiffness, pile 


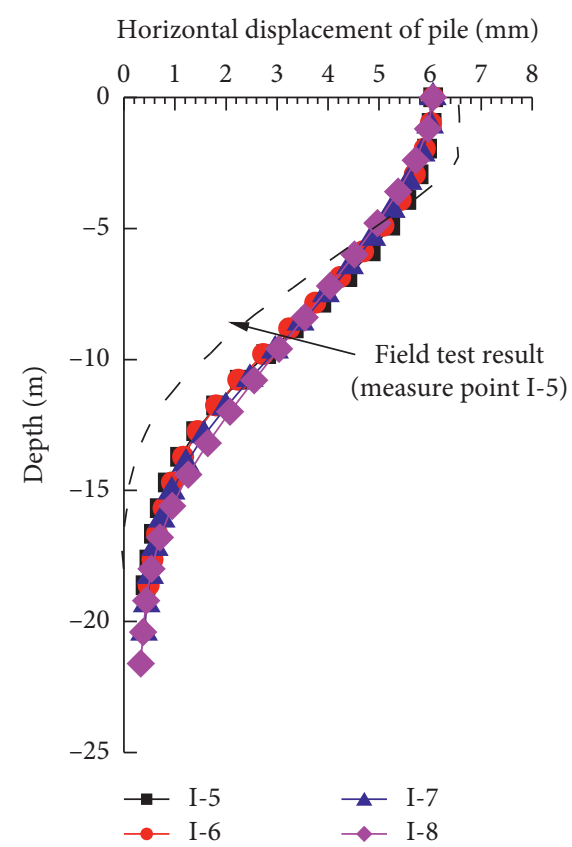

FIGURE 19: Calculated horizontal displacements of the pile.

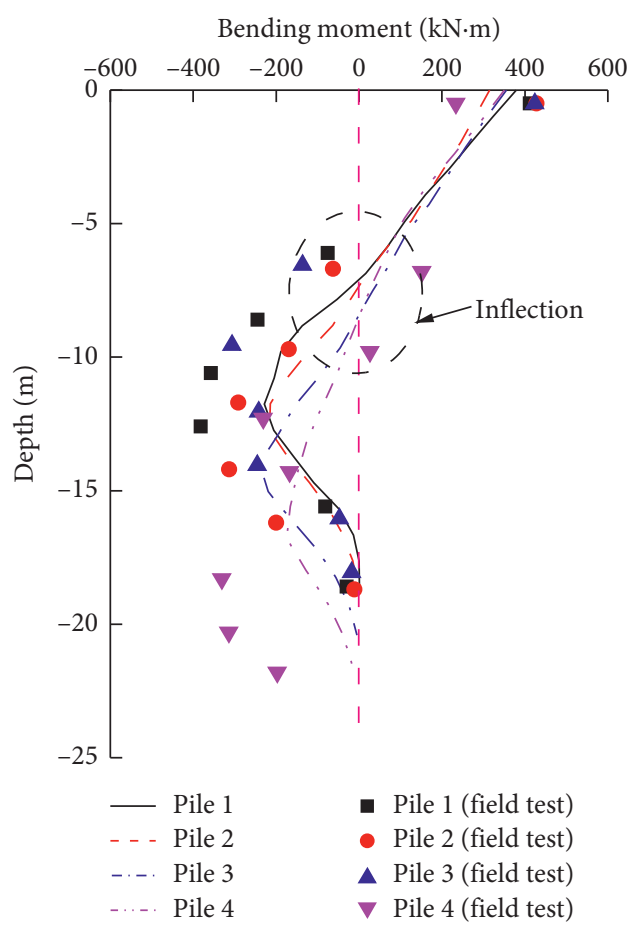

Figure 20: Calculated bending moments of various piles.

length, and positional relationship between the high and steep slope and the bridge pile foundation. The latter placed on a high and steep slope exhibits stress characteristics that are very different from those of a normal slide-resistant pile. The rigid constraint of the pile cap, the pile group effect, and the bending moment and shear force transferred by the pier act together. It causes the bridge pile foundation to exhibit a stress and deformation pattern that differs from that of the slide-resistant piles. In addition, the displacement of the surrounding inclined stratum also affects the vertical load capacity of the bridge pile foundation. These factors complicate the working mechanism of bridge piles' foundations on high and steep slopes.

With the development of numerical simulation techniques, various strength reduction methods have been proposed to analyze the stability of slopes and stress parameters of slope structures. Several examples include strength reduction methods based on finite element and finite difference techniques [33-36]. They represent useful tools for the analysis of the interactions between the high slopes and the corresponding structures under complex conditions.

Using a numerical limit analysis method, the ultimate failure state of the developed model is reached by reducing the strength during elastoplastic finite element or finite difference calculations. In this way, it is possible to identify the failure state of the slope and corresponding safety factor. The extreme conditions obtained by the numerical limit analysis can be considered as the extreme values reached by the slope under adverse loading conditions (such as rainstorm and increased external loading).

5.1. Numerical Simulation Results. Figure 21 shows the horizontal displacements calculated from the soil parameters at extreme conditions. The soil above the second row of the anti-slide piles is relatively stable under the specified conditions. A large horizontal displacement is observed for the first row of the slide-resistant piles. The sliding surface is developed from the middle area between the two rows of slide-resistant piles and ejected from the foot of the slope where the bridge foundation is located. At this moment, the displacement of the free surface near the bridge base position becomes larger and reaches $5.5 \mathrm{~cm}$. In the prototype section of the same site, two rows of the slide-resistant piles are used to prevent the occurrence of a landslide on the slope. While such an approach can be efficient under the extreme conditions, the bridge foundation at the riverside is also located on the slope and thus may be significantly deformed.

Figure 22(a) shows the horizontal displacements of the first row of the slide-resistant piles computed under the extreme working conditions. The slide-resistant piles experienced cantilever-type horizontal displacements with the maximum value observed for the pile top. Although the first row of the slide-resistant piles contains anchor cable slideresistant piles, the use of the prestressed anchor cable does not change the cantilever displacement mode. Three slideresistant piles (28\#, 29\#, and 30\#) are simulated in our study. From Figure 22(a), it can be seen that the displacement of the middle slide-resistant pile 29\# is almost identical to the displacements of the other piles. Hence, the arching effect of the soil on the pile displacement is negligible.

Figure 22(b) shows the horizontal displacements of the bridge pile foundations under the extreme working conditions. These foundations are labeled pile 1-pile 4 following the order from the mountainside to the riverside (free surface side). As shown in the figure, the displacements at 

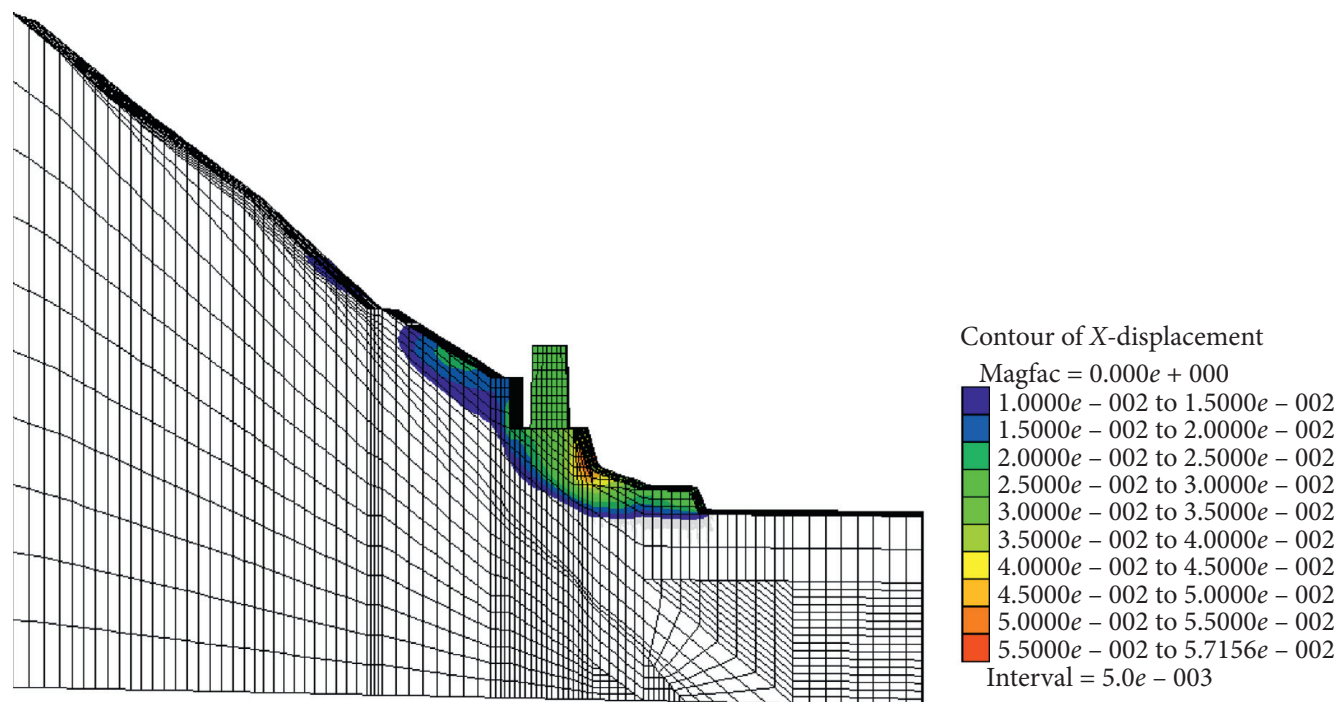

Figure 21: Horizontal displacements of the stratum (units: m).
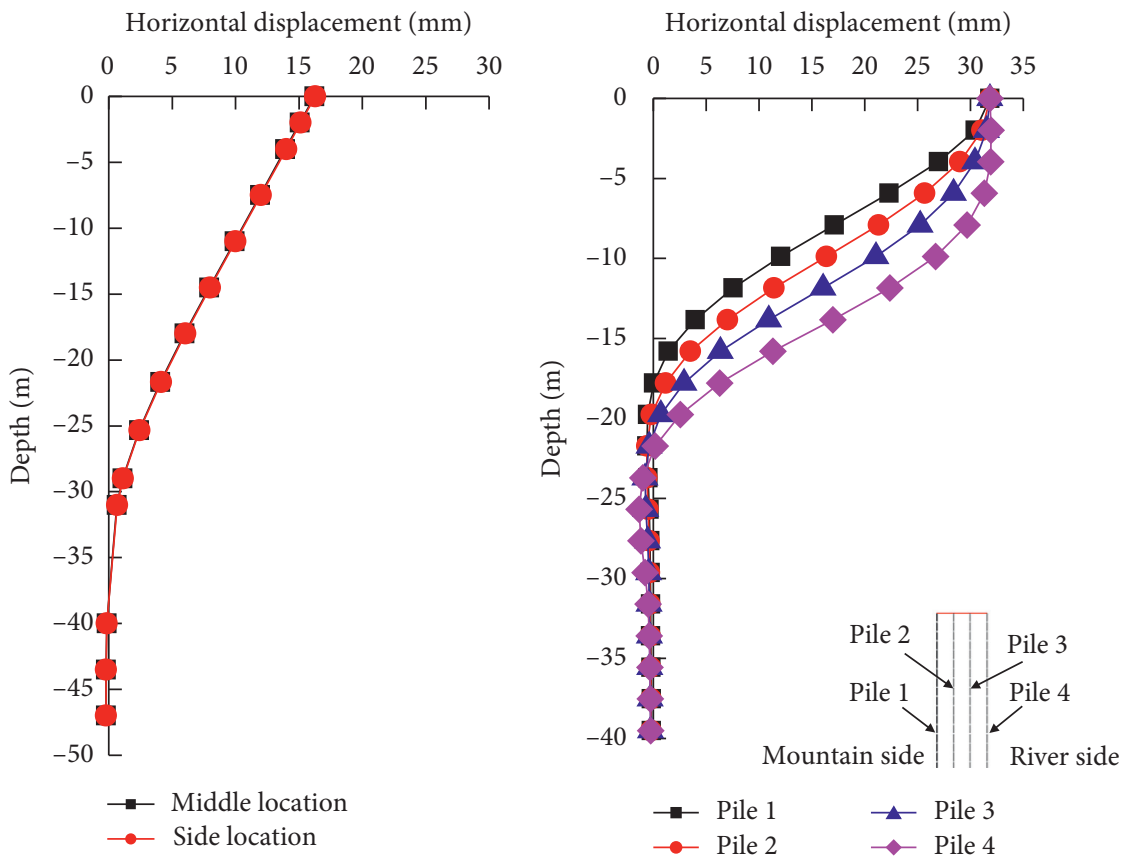

(a)

(b)

Figure 22: Continued. 


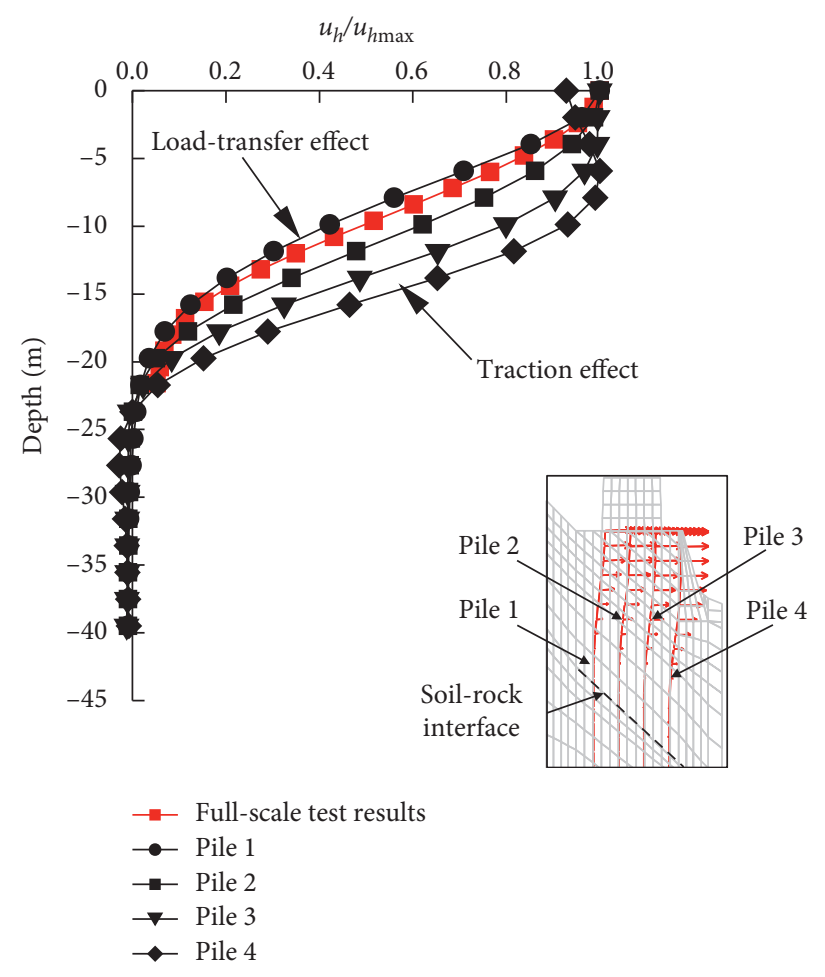

(c)

FIgURe 22: Horizontal displacements of the bridge pile foundation and slide-resistant piles under the extreme working conditions. (a) Slideresistant pile. (b) Pile foundation of the bridge. (c) Comparison with the full-scale test results.

the pile tops are almost the same due to the constraining effect of the pile cap. However, different displacement modes are observed for piles 1-4. For pile 1, the maximum horizontal displacement occurred at the pile top, and the deformation of its body is primarily caused by the displacement of the pile cap. However, for pile 4 , the maximum horizontal displacement occurred not at the pile top, but at a depth of $10 \mathrm{~m}$ below the pile cap. The horizontal displacement at the pile top is $25.55 \mathrm{~mm}$, which exceeds the maximum allowable horizontal displacement of the pile cap $(15.54 \mathrm{~mm})$. These results demonstrate that the bridge structure at the foot of the slope remains under landside threat despite the deployment of two rows of slide-resistant piles in this section.

As shown by the results of the analysis conducted above, for the bridge foundations built on the feet of high and steep slopes, the utilized piles will be subjected to an inclined load. Compared with pile 1 , pile 4 is located on a thicker unstable soil layer and closer to the free surface of the slope. Therefore, the horizontal displacement of pile 4 is affected by the inclined stratum more significantly than that of pile 1 . The horizontal displacement of the bridge pile foundation is greater than that of the slide-resistant pile at the same pile height. Specifically, the horizontal displacement at the top of the pile cap is 1.57 times greater than that at the top of the slide-resistant pile. Hence, the deformation of the bridge pile foundation is caused not only by the displacement of the slide-resistant piles but also by the sliding of the local slope itself.
In summary, under the extreme working conditions, the following displacement characteristics can be identified:

(1) The slide-resistant pile with prestressed anchor cable experiences a cantilever-type horizontal displacement with the maximum displacement occurring at the pile top. No differences in the horizontal displacement are observed for different slide-resistant piles located at the same pier.

(2) The displacement modes are different for different piles in the bridge pile foundation moving from the mountainside to the riverside. Specifically, the displacements of the piles located near the mountainside exhibit the cantilever properties, while the maximum horizontal displacement in the pile body section can exceed that at the pile near the riverside.

(3) The deformation of the bridge pile foundation is affected by both the displacement transmitted from the slide-resistant pile and sliding of the local slope itself.

(4) The safety of the bridge is compromised once the horizontal displacement at the top of the pile exceeds the threshold value.

Figure 22(c) shows the comparisons between the fullscale test results and the numerical simulation results. In Figure 22(c), $u_{h}$ is the horizontal displacement of the piles, and $u_{h \max }$ is the maximum horizontal displacement of the piles. The full-scale test only reflects the load transfer 
induced by the deformation of the slide-resistant pile. Therefore, the deformation component of the bridge foundation can be obtained. From Figure 22(c), the deformation of pile 1 is in accordance with the full-scale test results. However, the deformations of piles 2-4 are greater than the full-scale test results, which show that the additional deformation induced by the slope movement appears (see Figure 21). It is not difficult to find that the bridge pile foundation built close to the slide-resistant pile on a high and steep slope is simultaneously subjected to the load transferred from the slide-resistant pile and slope traction. After increasing the distance between the pile and the slideresistant pile, and decreasing the distance between the pile and the free surface, the dominant factor affecting the deformation and stress characteristics of the pile foundation is switched from the "load-transfer effect" of the slide-resistant pile to the "traction effect" of the slope itself. Such a transition yields different deformation and stress characteristics of the pile foundation at various lateral positions.

Figure 23 shows the bending moments of the bridge pile foundation calculated under the extreme conditions. The distribution of the bending moment follows different trends along the pile body for different piles. For pile 1, the bending moment is maximized at the pile top. However, the bending moment of pile 4 is minimized at the pile top, and its maximum value is obtained at a depth of $10 \mathrm{~m}$. In order to improve the resistance of the bridge structure to the horizontal thrust caused by a landslide, an envelope design or local reinforcement should be adopted to accommodate the maximum bending moment at the pile top or in the pile body.

5.2. Effect of Pile Length. The effect related to the length of the pile section embedded into the rock is one of the major factors affecting the stress generated in the bridge pile foundation. It essentially means that the rock mass surrounding the embedded pile section is relatively stable and will not create additional load for the pile foundation. Therefore, the pile foundation is primarily subjected to the load transferred from the piles located above the sliding surface. However, once the embedded section reaches a certain length, the further increase in the pile length does not significantly improve the loading capacity of the pile foundation (this limitation is known as the "embedment depth effect"). In the bridge pile foundation built on an inclined stratum, the embedded length is different although the total length is the same for all piles. In this study, a numerical simulation model is developed to analyze the stress and deformation characteristics of the pile foundation. The pile lengths equal to $40,35,30,25,20$, and $15 \mathrm{~m}$.

The horizontal displacement characteristics of the bridge pile foundation with different pile lengths are shown in Figure 24, which exhibits the following features:

(1) When the pile foundation is sufficiently long (above $30 \mathrm{~m}$ ), a relatively strong embedment effect can be caused by the rock mass. Therefore, the pile foundation undergoes consistent displacement under the horizontal thrust of the landslide. Specifically, at a

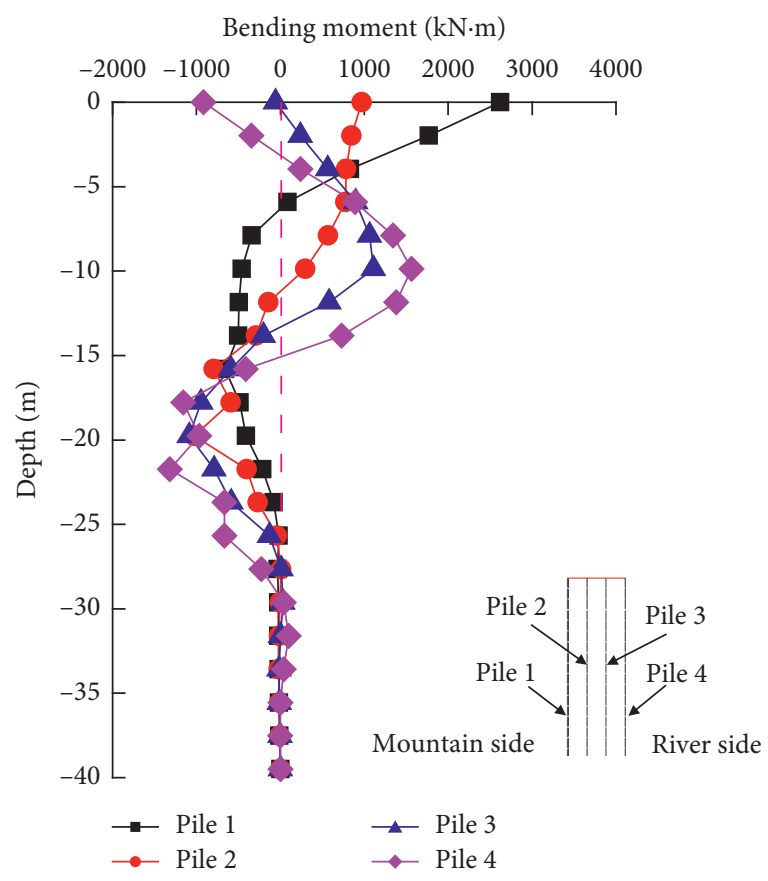

FIGURE 23: Bending moments of the bridge piles calculated under the extreme working conditions.

relatively long pile foundation, the pile body exhibits "flexible" bending characteristics and strong reverse bending that increases its flexural capacity. The analysis of the obtained results shows that the critical embedment depth of the bridge pile foundation under inclined load should be $4-5$ times greater than the pile diameter.

(2) Reducing pile length changes the displacement mode of the bridge pile foundation and attenuates the embedment effect of the rock mass. Significant displacement can be even observed at the bottom of the pile foundation in extreme scenarios. In the latter case, the pile exhibits "rigid" characteristics when its body is almost free from reverse bending and possesses a small degree of inclination, as shown in Figure 24(f).

(3) Owing to the stratum inclination, piles 1-4 exhibit different embedment depths. As a result, their sensitivities to the pile length are also different. Pile 4 is located on a thick sliding mass and, therefore, is most sensitive to the change in the pile length. A large displacement is observed for the embedment end of pile 4 when its length is reduced to $25 \mathrm{~m}$. However, pile 1 has a relatively long section embedded into the rock layer. Therefore, the deformation mode of this pile only starts to change when its length is reduced to $20 \mathrm{~m}$.

(4) When designing a bridge pile foundation on a high and steep slope, its deformation capacity and embedment effect under a horizontal load should be determined in addition to the vertical loading capacity. 


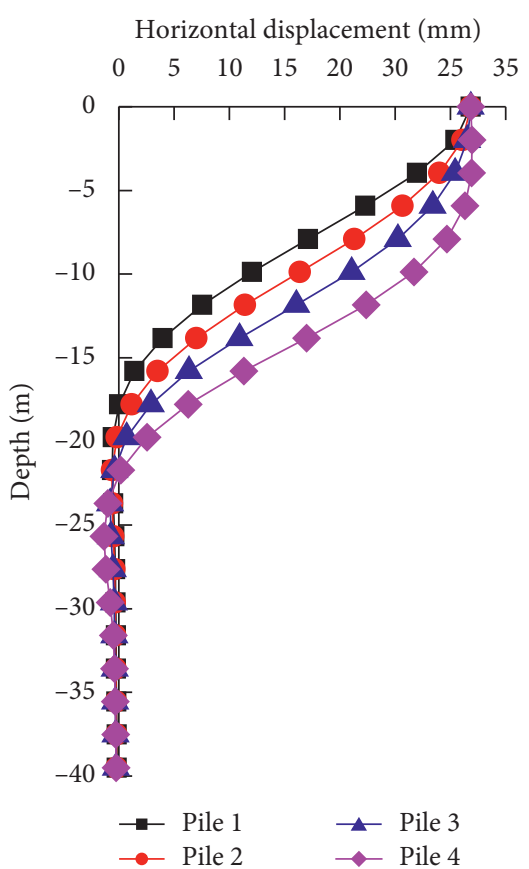

(a)

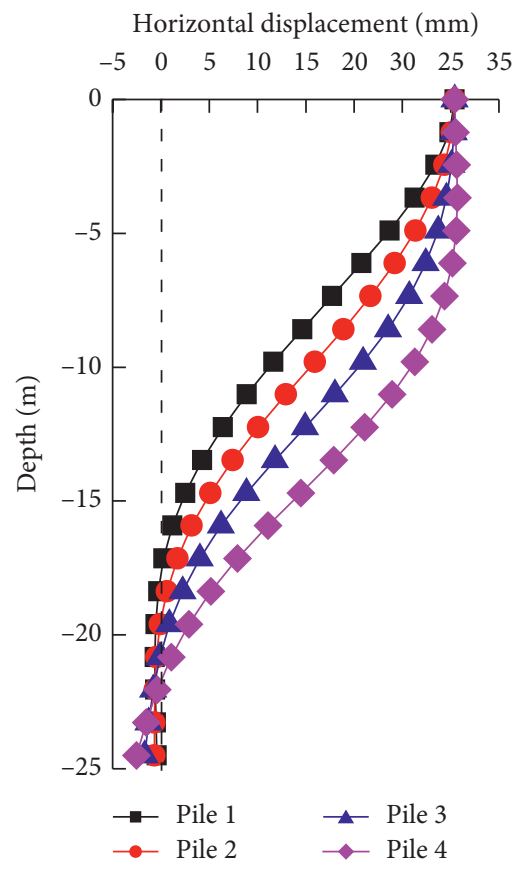

(d)

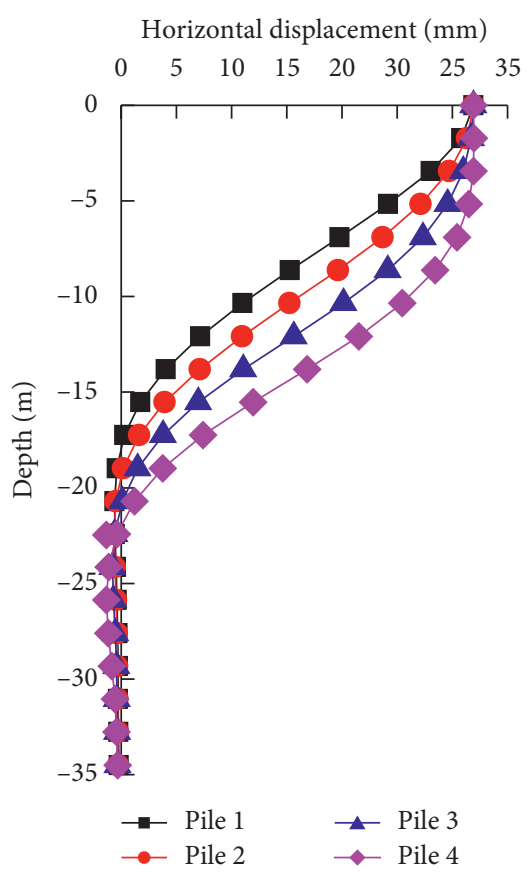

(b)

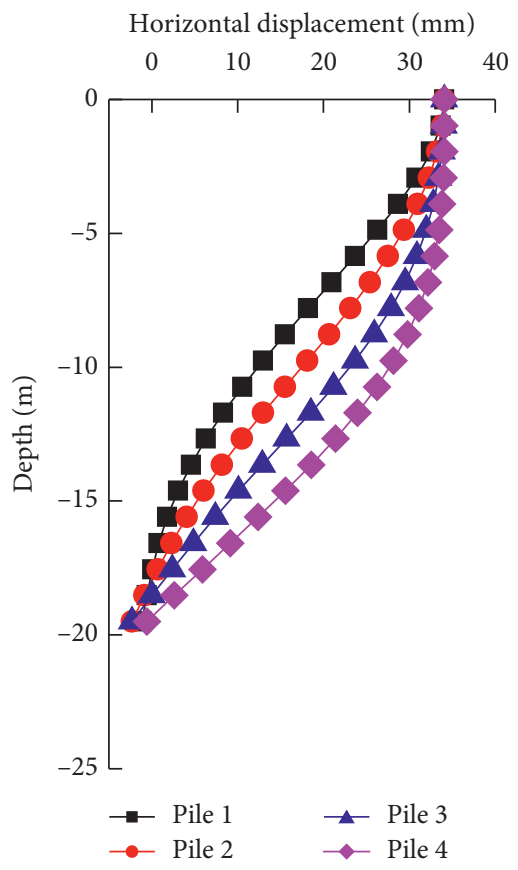

(e)

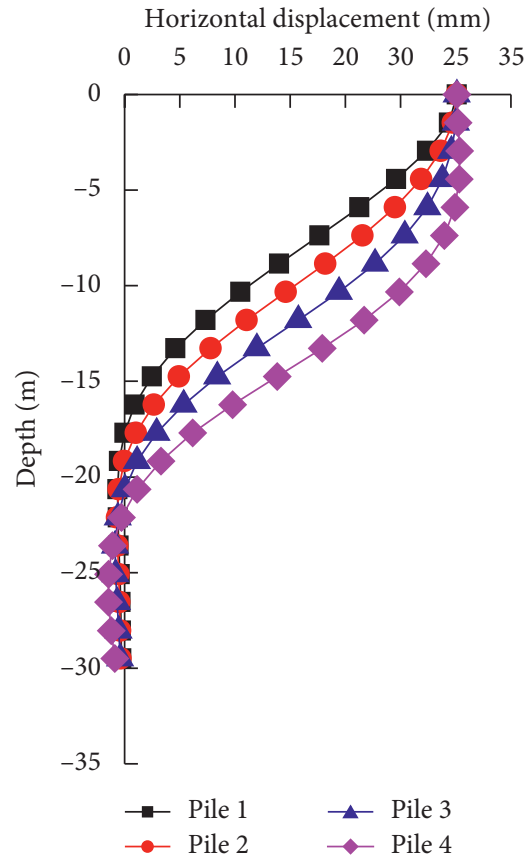

(c)

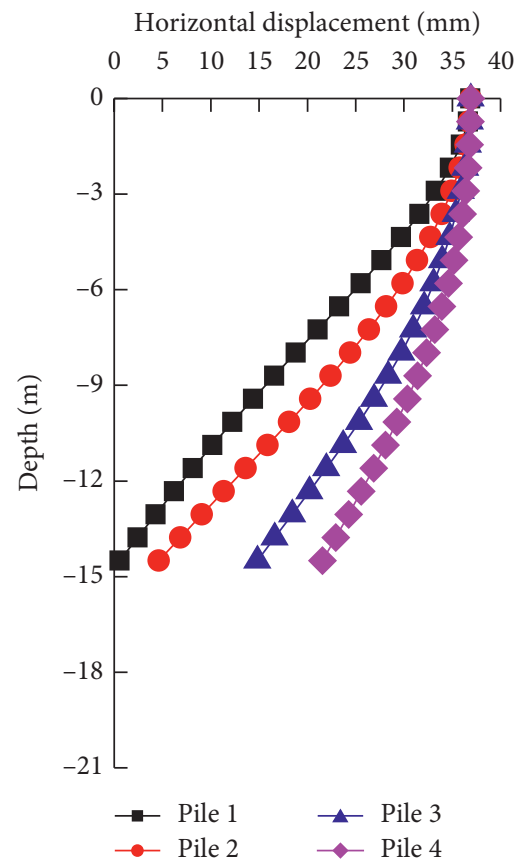

(f)

Figure 24: Effect of the bridge pile length on the pile deformation. (a) $l=40 \mathrm{~m}$. (b) $l=35 \mathrm{~m}$. (c) $l=30 \mathrm{~m}$. (d) $l=25 \mathrm{~m}$. (e) $l=20 \mathrm{~m}$. (f) $l=15 \mathrm{~m}$.

Figure 25 shows the changes in the bending moments of the bridge pile foundation with the pile length, which demonstrates the following features:

(1) Similar to the deformation properties, different distribution patterns of the bending moment are observed for different piles. For piles 1 and 2, the maximum bending moment is measured at the pile top. When the pile length is between 25 and $40 \mathrm{~m}$, the changes in the bending moments at the pile top and in the pile body with decreasing pile length are relatively small. When the pile length is smaller than $20 \mathrm{~m}$, the bending moment at the pile top starts to increase, and the bending moment at the pile bottom decreases substantially, indicating that the pile embedment effect has become very weak.

(2) For piles 3 and 4, two reverse bends are detected on the pile body when the pile length is relatively long. The maximum bending moments are obtained at 


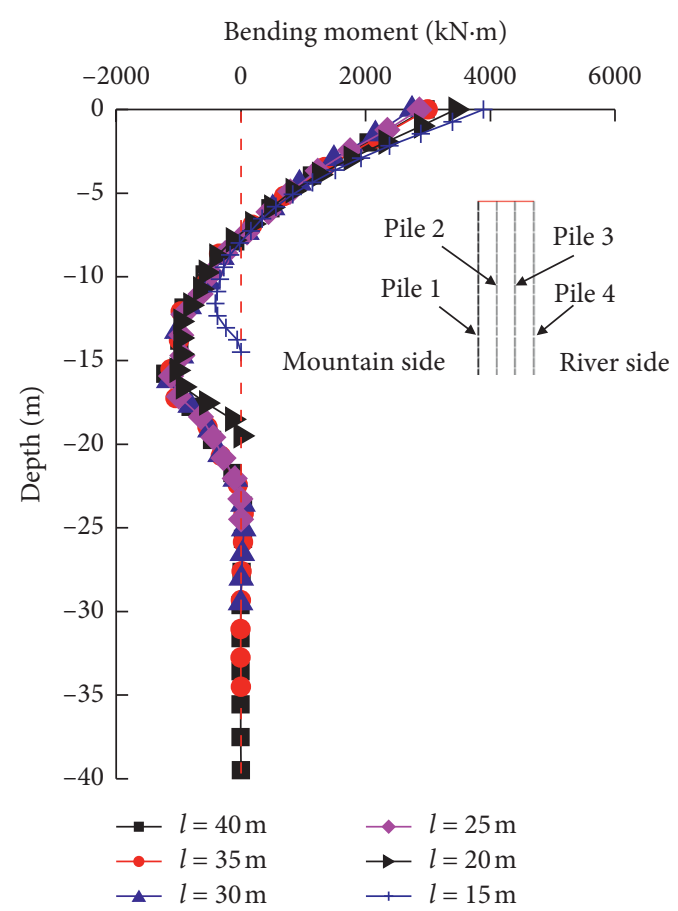

(a)

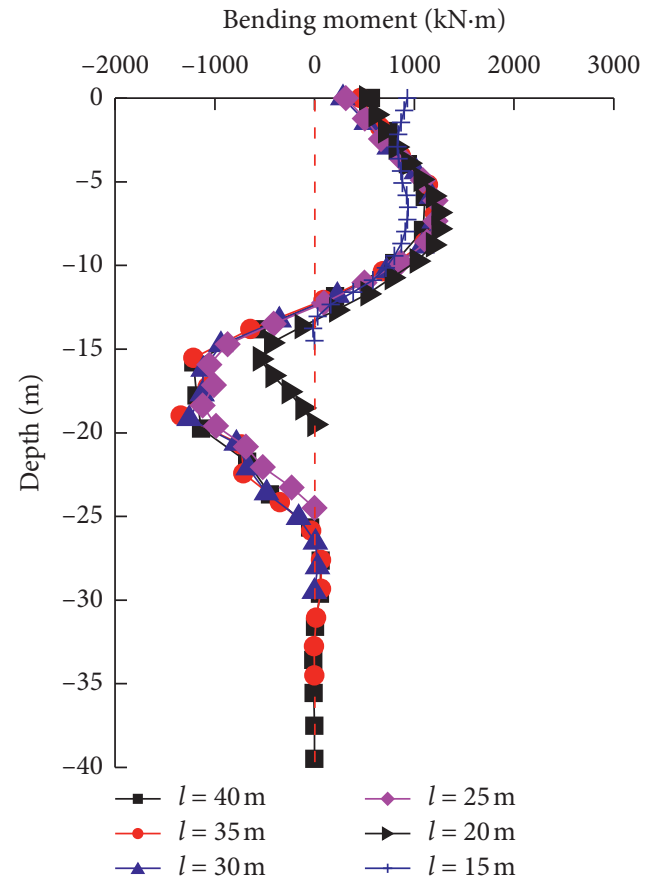

(c)

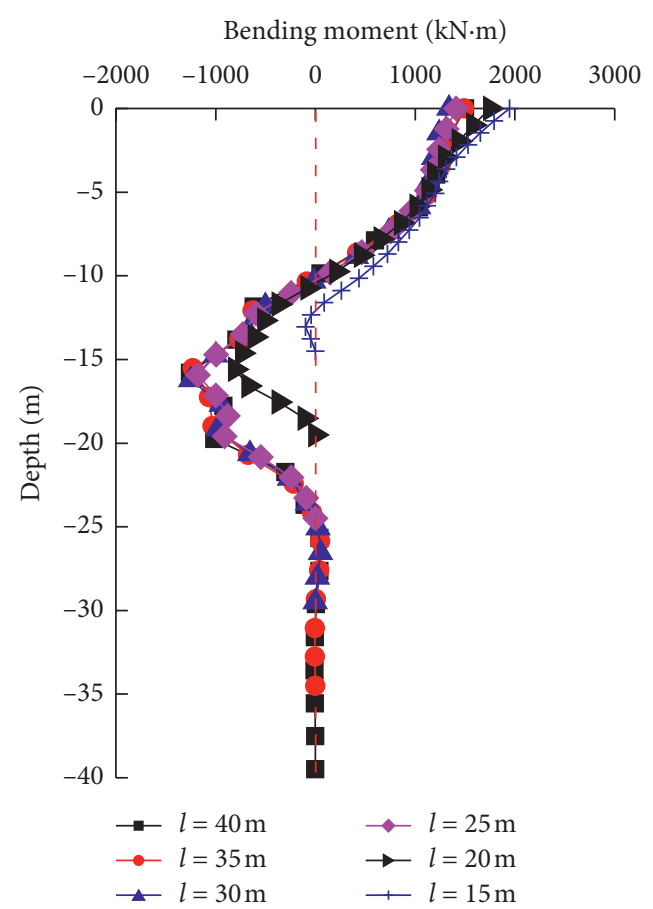

(b)

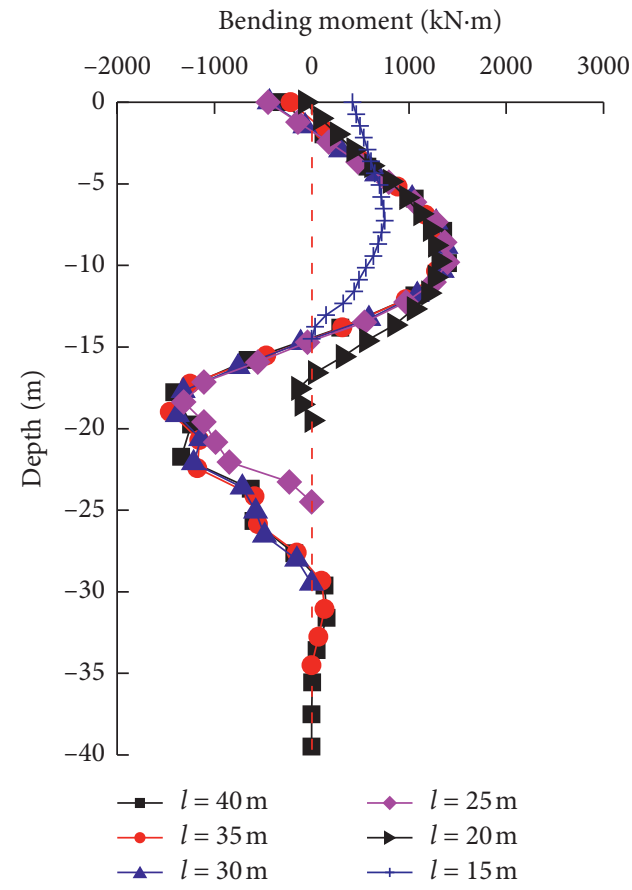

(d)

FIGURE 25: Influence of the pile length on the bending moment of the pile body. (a) Pile 1. (b) Pile 2. (c) Pile 3. (d) Pile 4.

depths of 10 and $20 \mathrm{~m}$ below the pile top, respectively. When the pile length is smaller than $20 \mathrm{~m}$, the further reduction in the pile length abruptly decreases the bending moment at the pile bottom and increases it at the pile top. In this case, the pile stress characteristics start to change and the reverse bending process becomes less significant. The bending moment of the pile becomes a representative feature of the rigid pile. In particular, the bending moment of the body of pile 4 decreases very 
rapidly when the pile length is reduced to $15 \mathrm{~m}$. It indicates that the landslide resisting capacity of the pile body is drastically decreased.

5.3. Effect of Pile Diameter. The stiffness of the bridge pile foundation is a key factor affecting its overall flexural capacity. At the same pile spacing, varying the pile diameter significantly affects the integrity of the pile foundation and pile group effect. In this study, we calculated the deformation and stress characteristics of various piles with the diameters $d=0.8,1,1.25,1.5$, and $2 \mathrm{~m}$. Figure 26(a) shows the horizontal displacements of pile 1 calculated at different diameters. With increasing pile diameter, the stiffness of the pile body continues to increase and the horizontal displacement at the pile top decreases substantially.

The horizontal displacement of the pile body shows different trends in the shallow and deep soils. The pile horizontal displacement in the shallow soil changes more significantly at different pile diameters. At a depth of $10 \mathrm{~m}$ below the pile top, the horizontal displacement of the pile body decreases with increasing pile diameter. However, at depths greater than $10 \mathrm{~m}$, the horizontal displacement of the pile body increases slightly with increasing pile diameter, which can be attributed to its higher stiffness.

Figure 26(b) displays the bending moments of the pile body calculated at different pile diameters. It shows that increasing the diameter of the pile foundation increases the flexural rigidity and bending moment absorbed by this body. For pile 1, a reverse bending point is detected at a depth of $10 \mathrm{~m}$ below the pile top. The bending moment at this location does not change with increasing pile diameter.

The variations of horizontal displacement of pile cap with different pile diameter and pile length are shown in Figure 27. The horizontal displacement of pile cap decreases linearly with the increasing pile diameter. However, when the pile length is greater than the critical embedment depth, the horizontal displacement of the pile cap will no longer decrease. The control value of pile cap is $15.54 \mathrm{~mm}$. Therefore, increasing the pile diameter is an effective way to decrease the bridge movement under extreme conditions. However, the effect of increasing the pile length is not obvious.

5.4. Effect of Pile Foundation Location. During the calculation, the bridge foundation is set to different locations along the slope for analyzing its deformation and stress characteristics. Figure 28 shows the numerical models constructed for the bridge foundation placed at different locations along the slope. Here, the bridge foundation is located between the two rows of slide-resistant piles but closer to the second row and at the toe of the slope.

Figure 29(a) presents the horizontal displacements of the stratum calculated for the bridge pile foundation placed at the top of the slope. The slope between the two rows of slide- resistant piles is relatively stable. A landslide may occur under the extreme working conditions on the slope below the first pile row. For the bridge pile foundation, it forms a relatively stable structure with the two rows of slide-resistant piles on both sides. Therefore, the bridge pile foundation experiences only a small horizontal displacement under the extreme working conditions.

Figure 29(b) displays the horizontal displacements of the stratum calculated for the bridge pile foundation placed at the toe of the slope. It shows that the horizontal displacement of the stratum mainly occurs on the slope below the first row of the slide-resistant piles. The soil between the two pile rows undergoes only a slight displacement and is generally stable. The bridge pile located at the foot of the slope acts like a slide-resistant pile to prevent its sliding. The soil below the first row of slide-resistant piles experiences a relatively large local displacement (down to a depth of around $6 \mathrm{~cm}$ ) without causing any instability.

Figure 30 compares the horizontal displacements calculated for the bridge pile foundation placed in the top sections of the slope. Compared with the results of Figure 22(b), when the bridge foundation is placed at the top of the slope, the slide-resistant piles on its both sides strongly restrict the displacement of the local slope. Therefore, the top of the pile foundation experiences a small displacement. Specifically, the horizontal displacement at the pile top is reduced by $80 \%$ from 30.5 to $5 \mathrm{~mm}$. Besides, owing to the "traction effect" of the slope soil between the two rows of slide-resistant piles, the location of the maximum horizontal displacement on the bridge pile shifts downwards significantly. In particular, the location of the maximum horizontal displacement of pile 4 is shifted to a depth of around $12 \mathrm{~m}$ below the pile top.

In order to determine how displacement is transferred from the slide-resistant piles to the pile foundation of the bridge, we varied the distance $H$ between them. Calculations were performed at $H=2.3,4.7,6.9$, and $8.2 \mathrm{~m}$, and the obtained horizontal displacements of the bridge foundation are shown in Figure 31.

From the obtained data, the following conclusions can be made:

(1) After reducing $H$, the horizontal displacement at the top of the bridge pile foundation decreases accompanied by the displacement reductions along the pile body above the embedded end.

(2) As the value of $H$ decreases, the bridge foundation becomes closer to the first row of slide-resistant piles. It transfers deformation from the slide-resistant pile more effectively. The bridge foundation also becomes closer to the free surface of the slope. The amount of soil in front of the pile foundation that restricts the horizontal displacement decreases. Therefore, the "traction effect" induced by the slope becomes more significant, which contributes to the displacement of the bridge foundation. This phenomenon also 


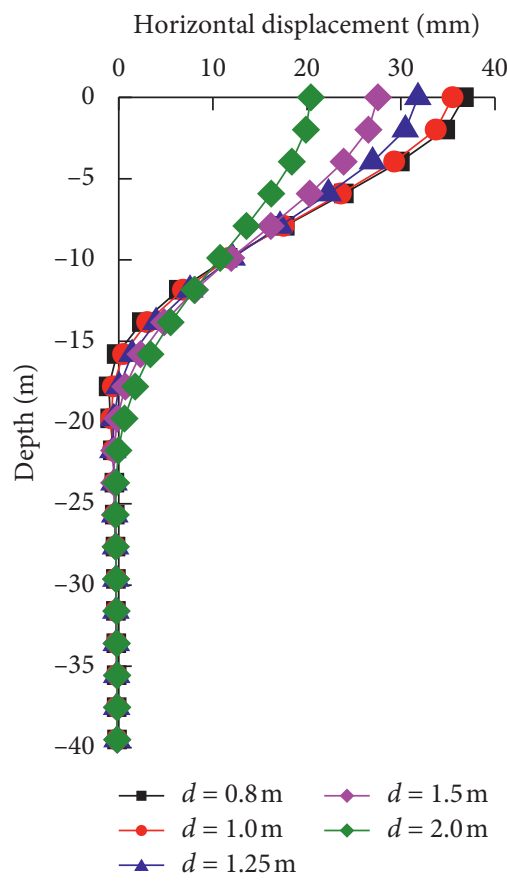

(a)

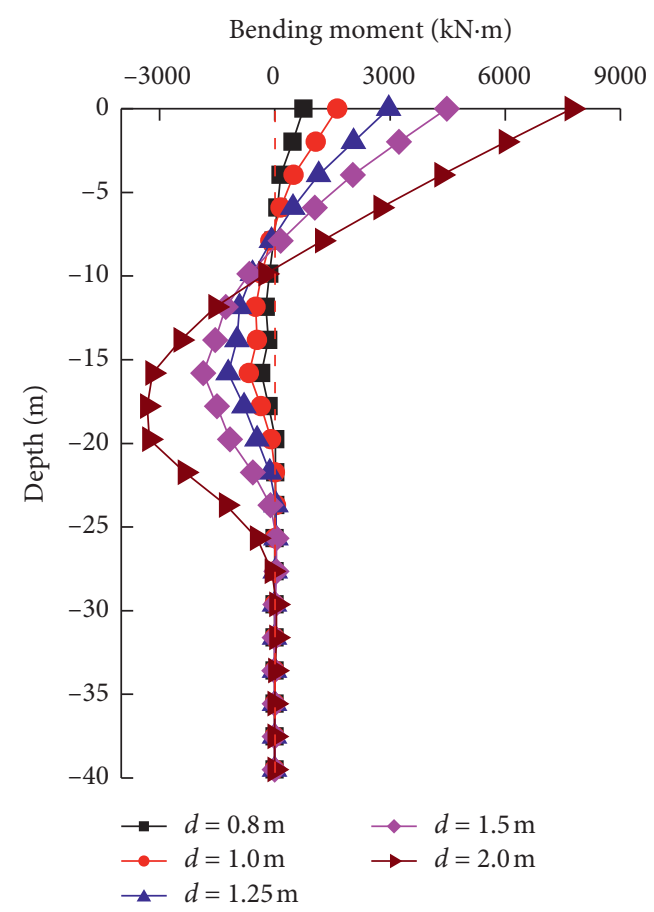

(b)

FIGURE 26: Influences of the pile diameter on the pile deformation and bending moment. (a) Pile deformation. (b) Pile bending moment.

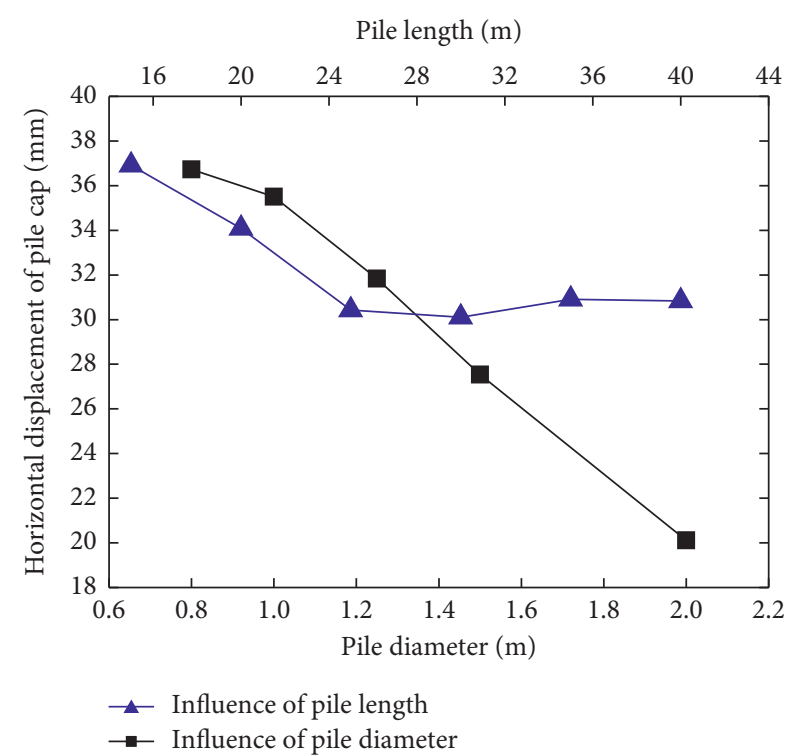

FIGURE 27: Variations of horizontal displacement of pile cap with the different pile diameter and pile length.

demonstrates that the deformation of the bridge foundation is caused by both the "load transfer effect" of slide-resistant piles and the "traction effect" of the sliding slope.

From the perspective of load transfer, when the bridge foundation is located on top of the slope (behind the sloperesistant pile of second row) or at the toe of the slope (far away from the slope-resistant pile), the deformation of bridge foundation under the extreme conditions is under the control value. However, the variations between the "traction effect" and the "load transfer effect" are related and inverse for the analyzed condition. Therefore, only adjusting the distance between the foundation and slide-resistant piles at the same location of the slope has only a minor effect.

5.5. Effect of Pile Arrangement. To analyze the effect of pile arrangement, numerical simulations were performed using four different pile layouts, as shown in Figure 32. The type A pile layout is the arrangement used in the actual project with pile diameter and spacing of 1.25 and $3.35 \mathrm{~m}$, respectively. The type B pile layout contains fewer piles in the foundation (only three rows of piles are arranged along the slope direction). In this configuration, the pile diameter is increased to $1.45 \mathrm{~m}$ to ensure that the vertical loading capacity of the pile foundation remains constant. The spacing between the piles along the slope direction is increased to $5 \mathrm{~m}$. The type $\mathrm{C}$ pile layout is a cross arrangement, in which two piles are placed along the centerline of the pile cap. The total number of piles remains unchanged. The type $\mathrm{D}$ pile layout is also a plum-shaped arrangement with different numbers of piles. The pile diameter and spacing are modified accordingly to maintain the same performance (the former parameter is equal to $1.6 \mathrm{~m}$ ).

Figure 33 shows the calculated horizontal displacements of different pile layouts. From the obtained data, the following features can be observed:

(1) The piles located near the mountainside exhibit a different deformation mode as compared with that of 


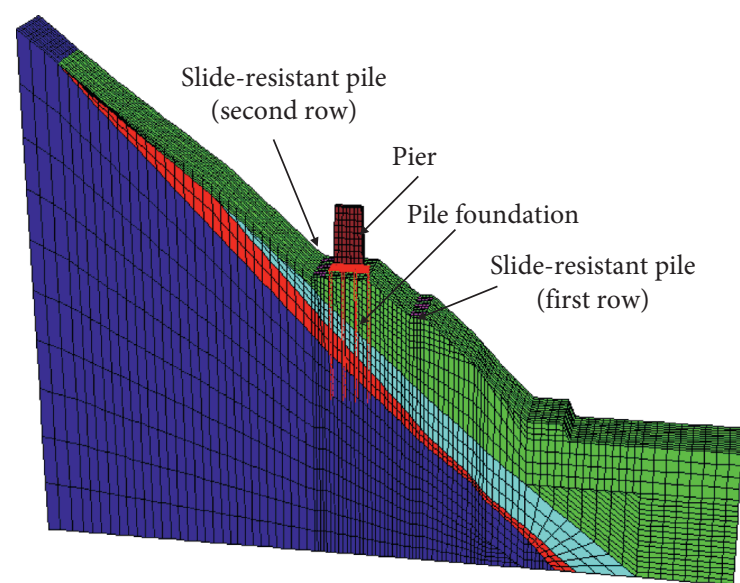

(a)

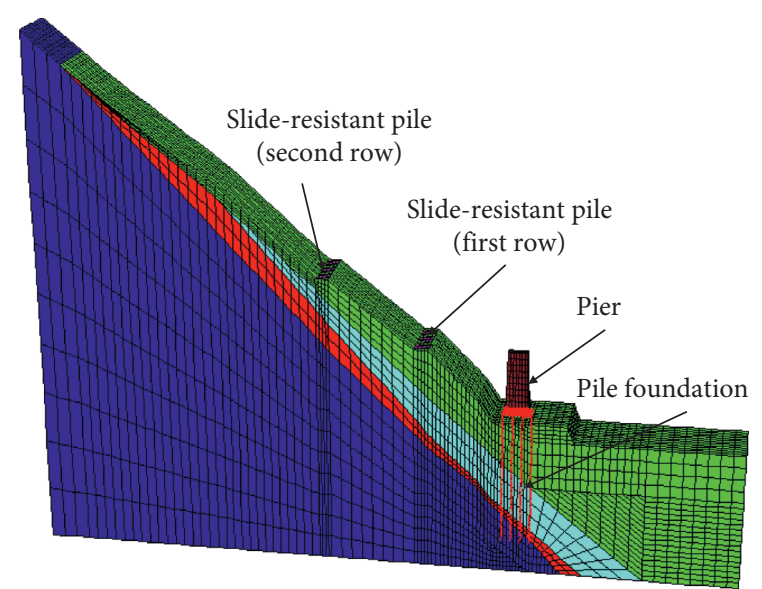

(b)

Figure 28: Calculation models used for the bridge foundation located at different positions along the slope. (a) At the top of the slope. (b) At the toe of the slope.

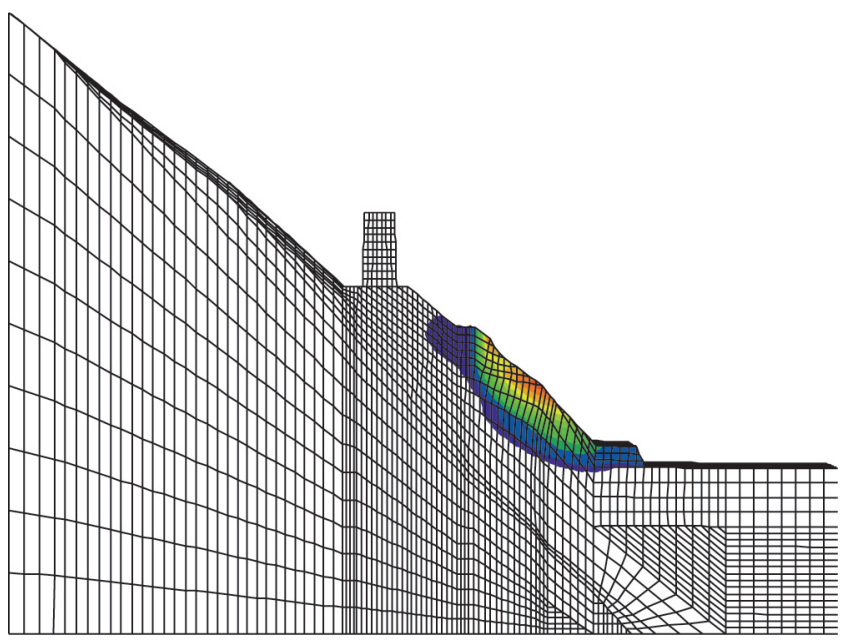

(a)

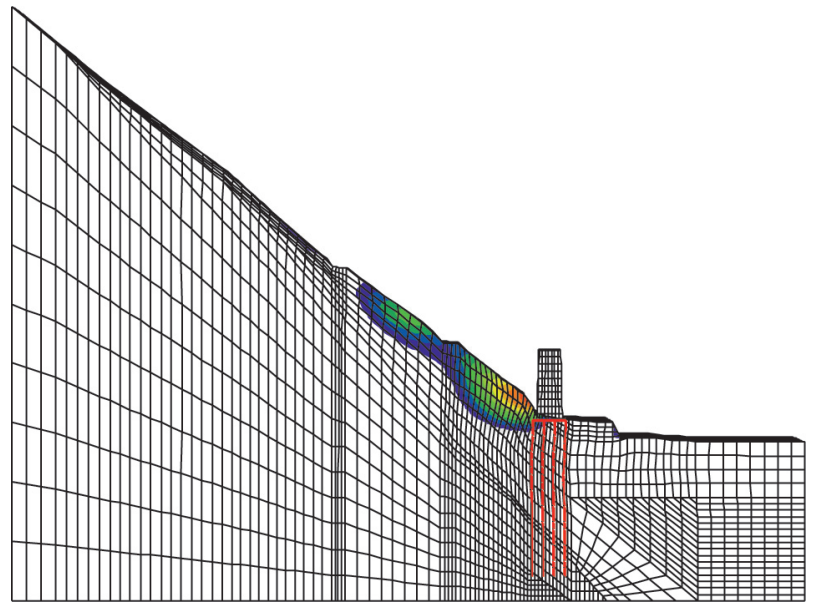

(b)

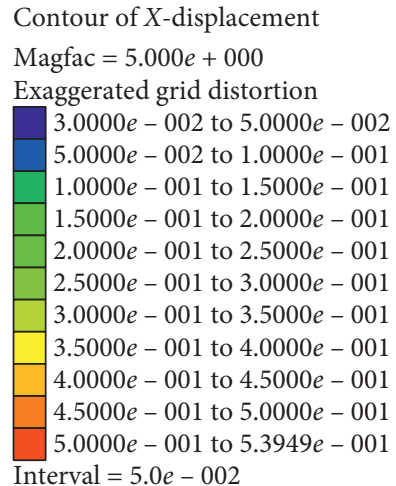

Contour of $X$-displacement

Magfac $=5.000 e+001$

Exaggerated grid distortion

$1.0000 e-002$ to $1.5000 e-002$

$1.5000 e-002$ to $2.0000 e-002$

$2.0000 e-002$ to $2.5000 e-002$

$2.5000 e-002$ to $3.0000 e-002$

$3.0000 e-002$ to $3.5000 e-002$

$3.5000 e-002$ to $4.0000 e-002$

$4.0000 e-002$ to $4.5000 e-002$

$4.5000 e-002$ to $5.0000 e-002$

$5.0000 e-002$ to $5.5000 e-002$

$5.5000 e-002$ to $5.9987 e-002$

Interval $=5.0 e-003$

Figure 29: Deformations of the stratum observed when the bridge foundation is located at different positions of the slope (units: $\mathrm{m}$ ). (a) At the top of the slope. (b) At the toe of the slope. 


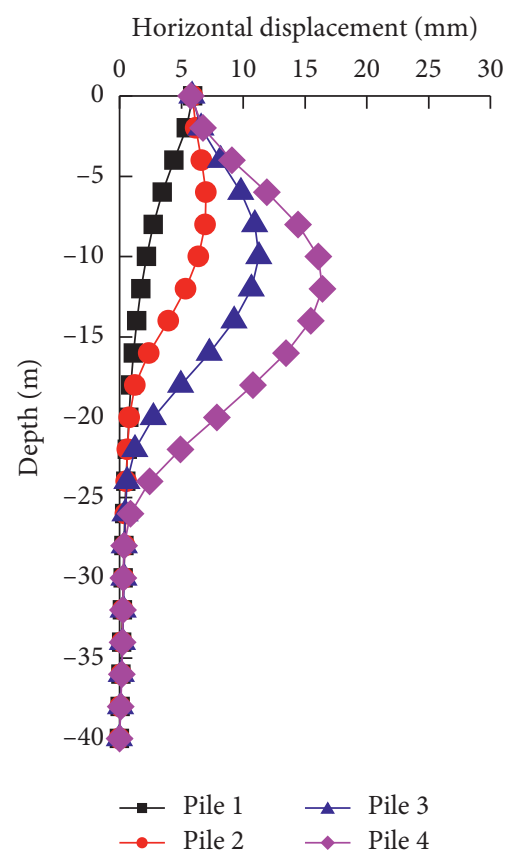

FIgURE 30: Horizontal displacements of the pile foundation placed at the top section of the slope.

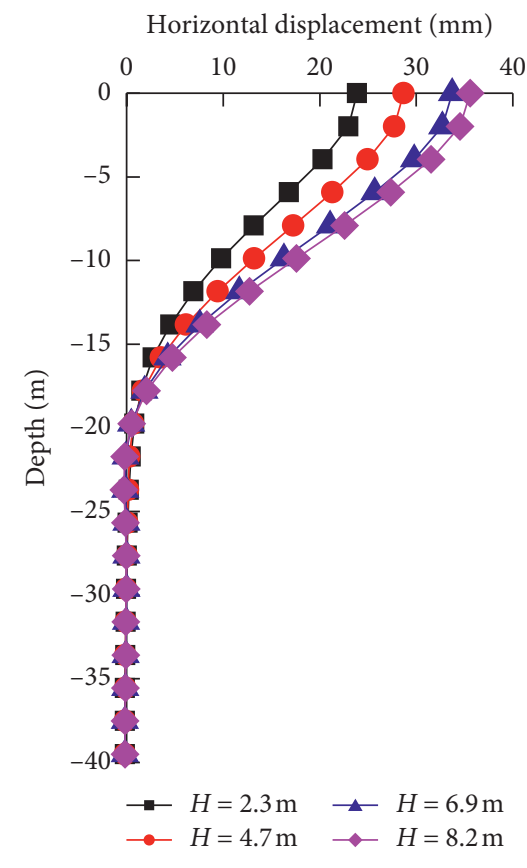

(a)

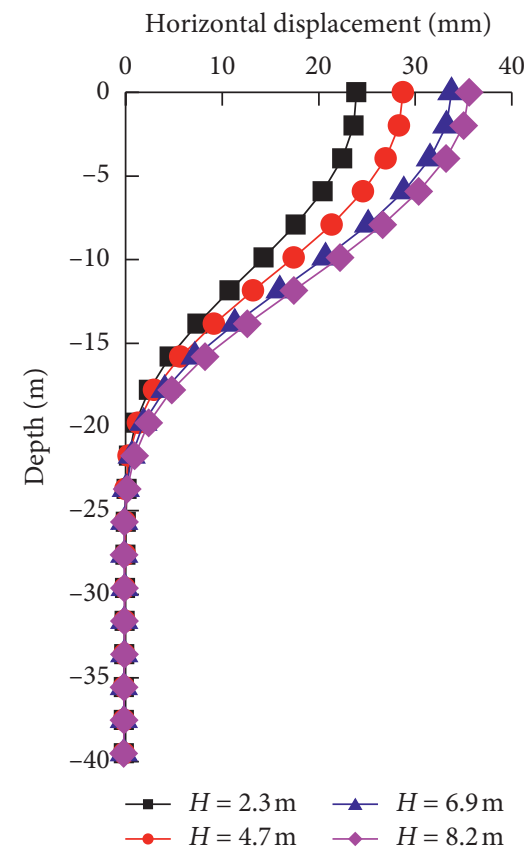

(b)

Figure 31: Continued. 


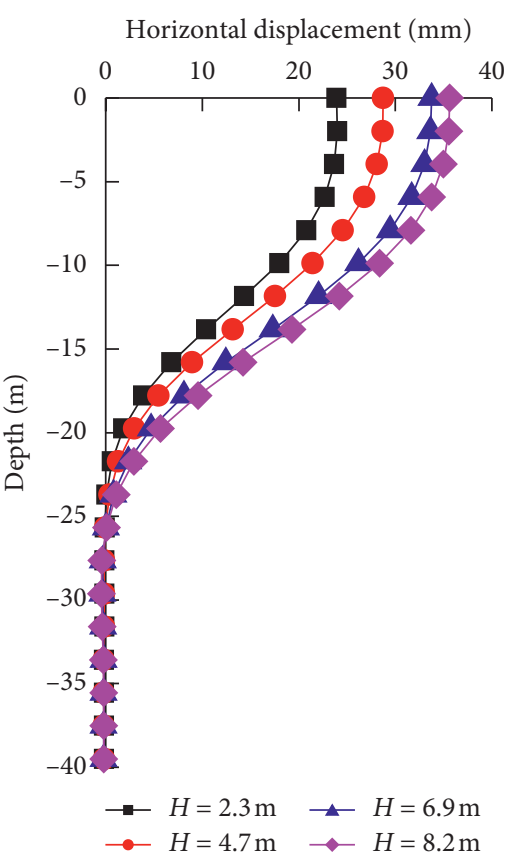

(c)

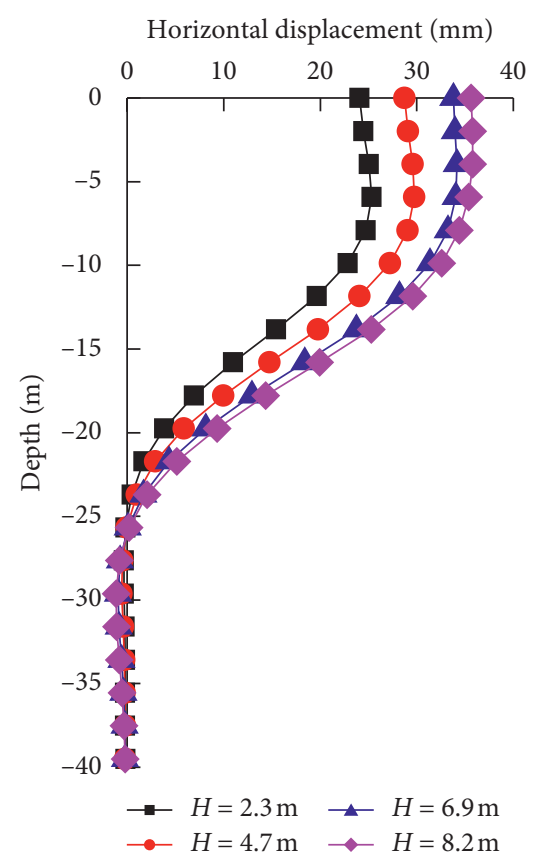

(d)

Figure 31: Influence of the distance between the foundation and slide-resistant piles on the pile deformation. (a) Pile 1. (b) Pile 2. (c) Pile 3. (d) Pile 4 .

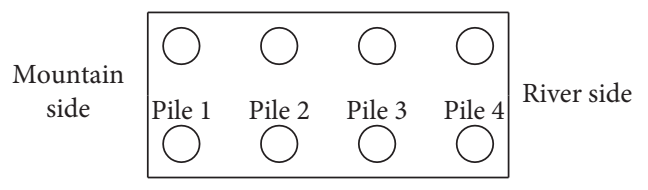

(a)

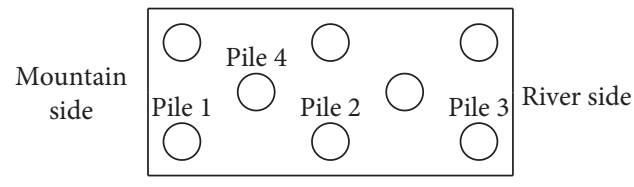

(c)

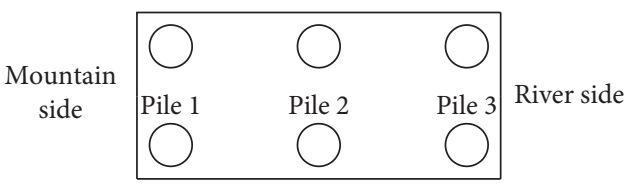

(b)

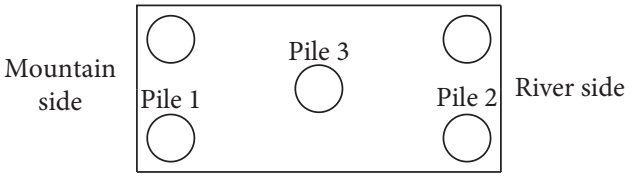

(d)

Figure 32: Different arrangements of the bridge piles used in this study. (a) Type A layout. (b) Type B layout. (c) Type C layout. (d) Type D layout.

the piles placed near the riverside. In addition, the pile located in the middle of the foundation along the transverse direction of the bridge shows an intermediate deformation pattern. These findings indicate that the deformation mode of the pile body is dependent on the relative location of the piles along the slope direction.

(2) After comparing the type A layout with the type B layout, it is found that the latter results in a significantly higher flexural rigidity and 10\% smaller horizontal displacement at the pile top.

(3) By using the piles with larger diameters in the type D layout, the horizontal displacement at the pile top is reduced by around $17 \%$ as compared with that in the type B layout.
(4) After satisfying the demand for the vertical loading capacity, using a layout with a larger diameter and smaller number of piles can be more beneficial for helping the bridge foundation to resist sliding forces along the inclined slope.

Figure 34 displays the bending moment distribution along the pile body from the mountainside to the riverside. The bending moments for different layouts show a similar pattern. Specifically, the location of the maximum bending moment moves downward below the pile top. As an example, its value is observed at the top of pile 1 and at a depth of $10 \mathrm{~m}$ below the top of pile 4. In addition, the bending moment at the top of pile 1 is substantially affected by the pile diameter. The maximum bending moment increases with increasing pile diameter and decreasing number of piles (type $\mathrm{A} \longrightarrow$ type $\mathrm{B} \longrightarrow$ type $\mathrm{D}$ ). 


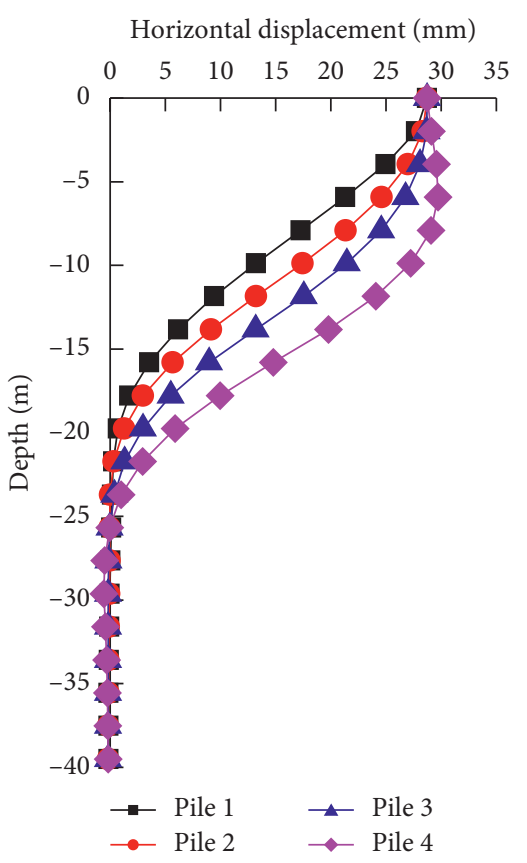

(a)

Horizontal displacement (mm)

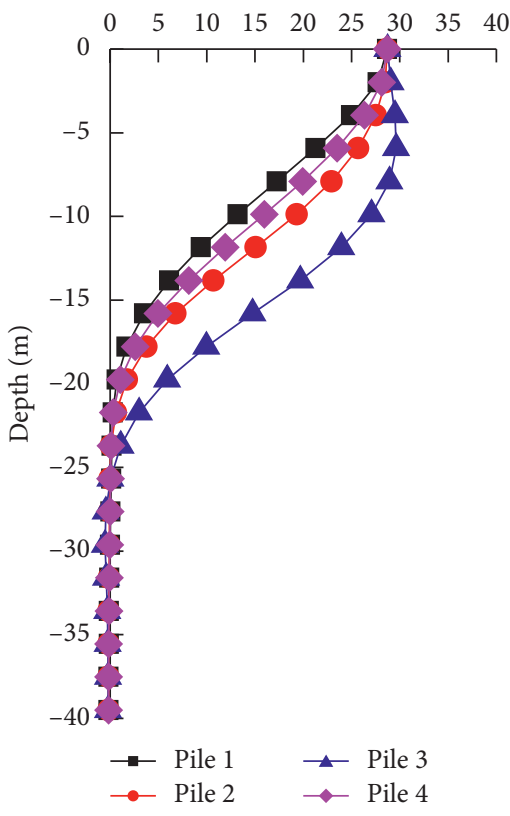

(c)

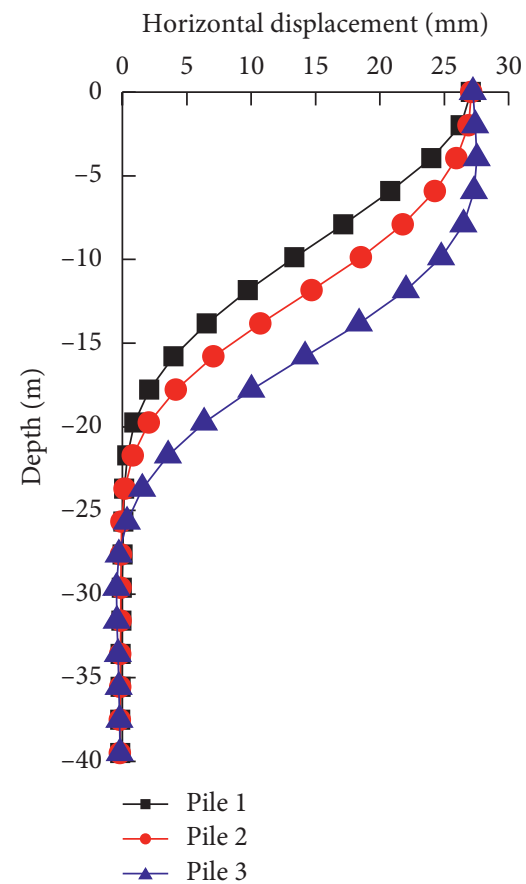

(b)

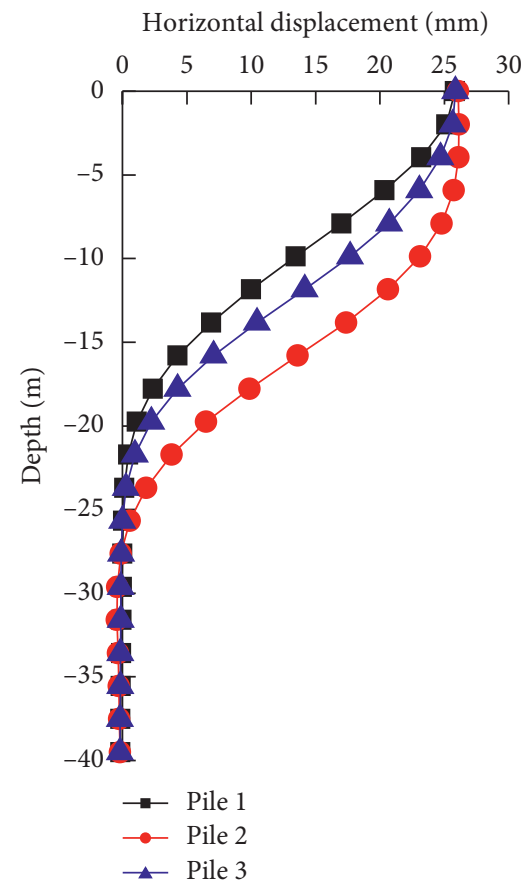

(d)

Figure 33: Influence of the pile arrangement on the pile deformation characteristics. (a) Type A layout. (b) Type B layout. (c) Type C layout. (d) Type D layout.

After comparing the type A and type C layouts, it has been found that the piles located at the same position exhibit almost the same bending moments. This phenomenon demonstrates that the pile bending moment is strongly correlated with its position. When using the cross-shaped layout, it does not significantly change the bending moment of the pile.
From the above analysis, the layout with a larger diameter and smaller number of piles is recommended to control the bridge foundation deformation. Turning the stability-based design of bridge foundation to the deformation-based design of slide-resistant pile and bridge foundation is necessary. 

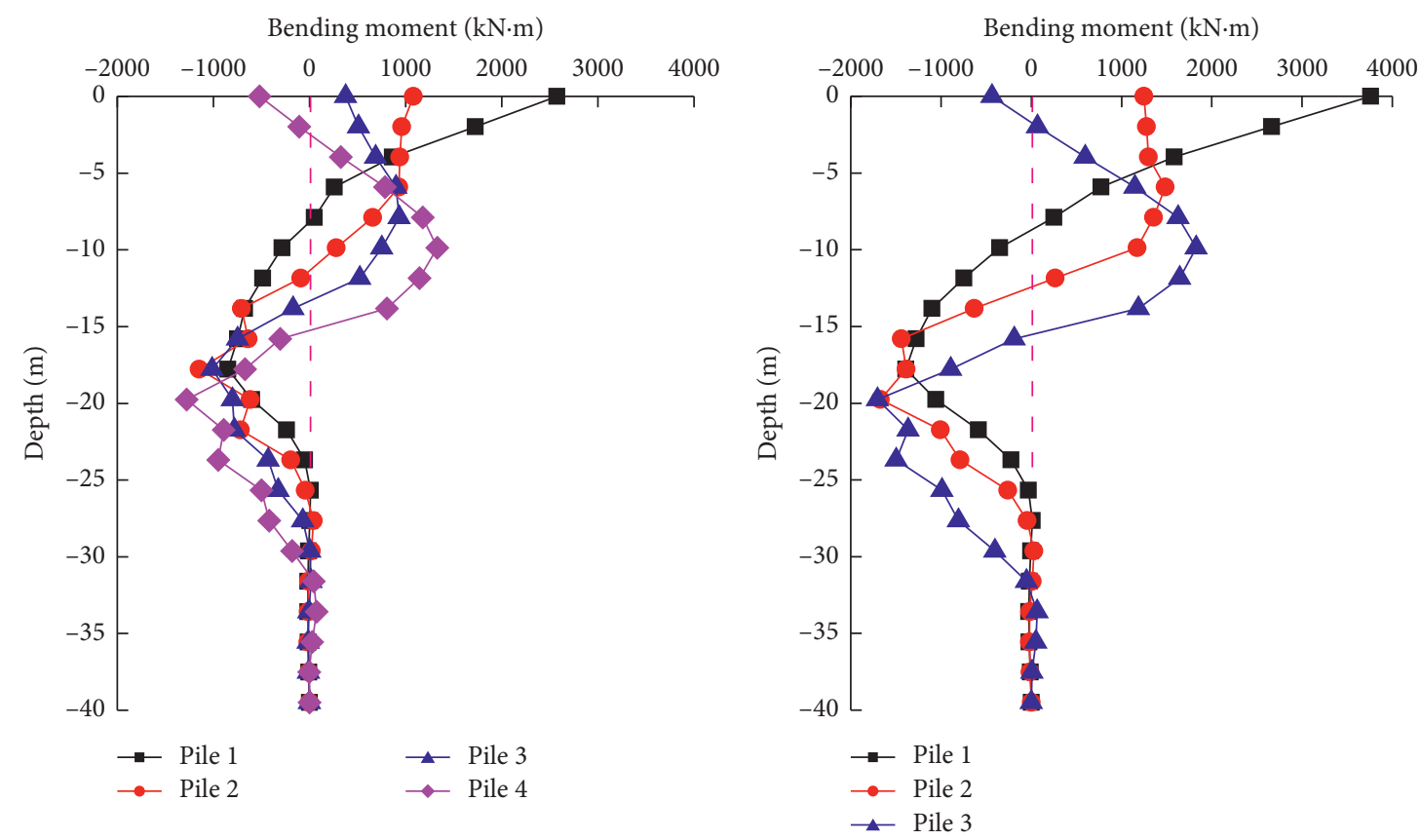

(a)

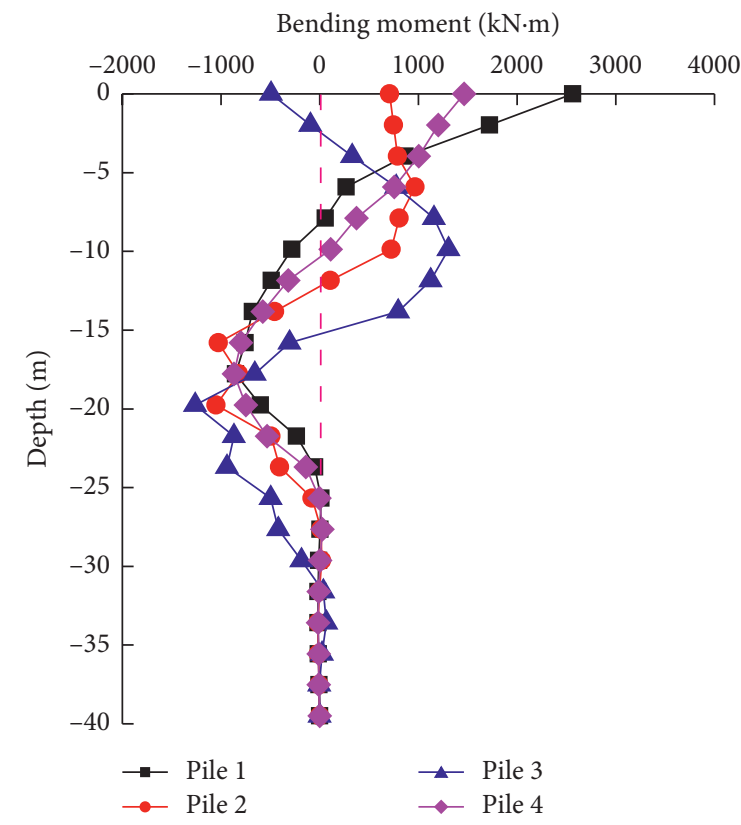

(c)

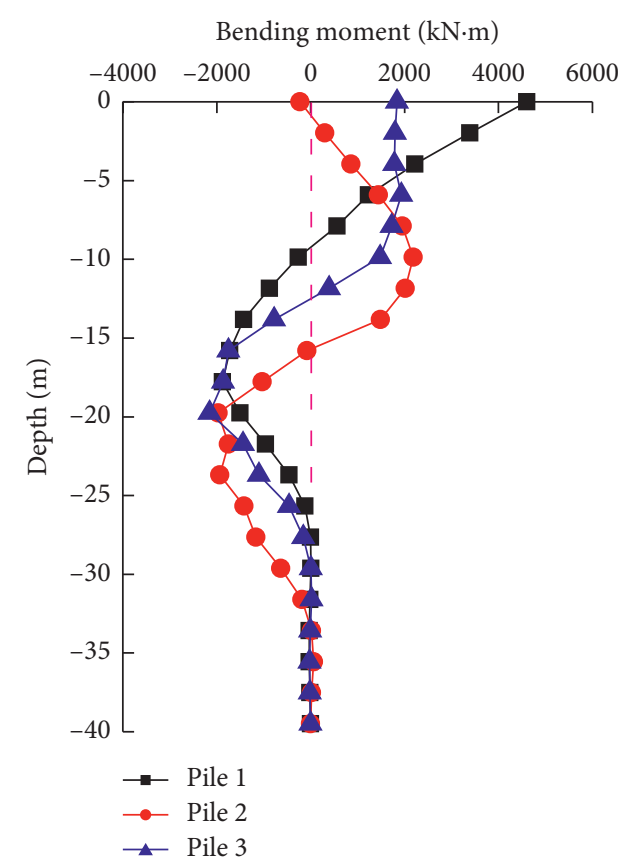

(d)

Figure 34: Influence of the pile arrangement on the bending moment. (a) Type A layout. (b) Type B layout. (c) Type C layout. (d) Type D layout.

\section{Conclusion}

In this study, we considered the engineering project of the newly built the railwayas a basis and analyzed the impact mechanisms of landslide on the bridge structure by performing both numerical simulations and full-scale field tests.
The deformation transfer mechanism between the slide-resistant pile and the adjacent structures is studied, and the displacement transfer ratio is obtained. From the parameter analysis, the optimum scheme of the bridge foundation is proposed. The following conclusions and recommendations have been formulated: 
(1) By utilizing comprehensive research methods involving both full-scale field tests and numerical calculations, we performed quantitative assessments of the stress and deformation characteristics of bridge structures under adverse working conditions. The horizontal displacement of the pile cap used in the real engineering project exceeds the maximum allowable limit of $15.54 \mathrm{~mm}$ outlined by the current specifications. When the displacement of the slideresistant pile at the top of the loading wall reaches $22.2 \mathrm{~mm}$, appropriate countermeasures should be taken to ensure the safety of the bridge.

(2) Under adverse working conditions, the displacement transfer ratios of the (a) soil between the slide-resistant pile and the pile cap, (b) bridge structure, and (c) soil on the side of the pile cap close to the riverside in the considered engineering project are equal to $0.70,0.73$, and 0.58 , respectively. The displacement transfer ratio from the slide-resistant pile to the bridge structure ranges between 0.56 and 0.90 .

(3) For the bridge structure built near the slide-resistant piles on a high and steep slope, the bridge pile foundation is simultaneously affected by the "load transfer effect" of the upper slide-resistant pile and the "traction effect" of the sliding slope. After increasing the distance between the pile foundation and the slide-resistant pile, the dominant factor affecting the deformation mode of the pile body is switched from the "load transfer effect" to the "traction effect." Such a transition yields different deformation and stress characteristics of the pile foundation at different lateral positions under the same pile cap. The safety of the bridge foundation on a slope can be improved by preventing the occurrence of landslides in the inclined strata where the bridge foundation is located. In order to reduce the "traction effect" induced by the sliding slope below the slide-resistant piles, the latter should be reinforced to reach the stability level in the proposed design. This will ensure a consistent safety level and stability throughout different sections of the slope and the supporting structure. In addition, the reinforced soil will also eliminate the unstable traction effect induced by the front sliding mass when the upper slide-resistant piles play their roles.

(4) Based on the impact mechanisms of the sliding slope on the bridge structure, one should prioritize the route selection and optimization of the bridge structure. When the stability of the slope below the slide-resistant piles is ensured, it is more beneficial to build the bridge foundation in the upper part or at the foot of the slope.

(5) A critical embedment depth exists for the bridge pile foundation built on a high and steep slope, which varies at different locations along the inclined stratum. The horizontal deformation and loading mode of the pile will change if the height of the pile foundation fails to satisfy the embedment requirement. Increasing the pile diameter will substantially improve the resistance of the bridge structure to the landslide thrust. However, the bending moment of the pile body also increases significantly. The deformation of the bridge pile foundation depends on its distance to the slide-resistant pile.

(6) For controlling the horizontal displacement of Data Availability, it is more advantageous to use the pile group with larger pile diameter and lower pile number, when the total vertical loading capacity of a bridge pile foundation is close to a target value.

Full-scale field tests in this study can reflect the actual stratum condition. However, extreme conditions such as earthquake and rainstorm cannot be tested. Centrifuge tests and shaking table tests are needed to further study the deformation of the bridge foundation under extreme conditions. Besides, the design method considering the loading transfer between the slide-resistant pile and the bridge foundation and the application of value engineering model need to be investigated further.

\section{Data Availability}

The data used to support the findings of this study are available from the corresponding author upon request.

\section{Conflicts of Interest}

The authors declare that there are no conflicts of interest regarding the publication of this paper.

\section{Acknowledgments}

This work was supported by the National Key R\&D Program of China (Grant No. 2018YFC1504904) and China Railway Corporation Research and Development of Science and Technology Plan Project (Grant No. P2018G001). The authors are grateful for their support.

\section{References}

[1] Y. Tang, H. Shu, Q. Xue et al., "Field monitoring-based and theoretical analysis of Baota Mountain landslide stability," Advances in Civil Engineering, vol. 2021, Article ID 6699917, 16 pages, 2021.

[2] H.-J. Hou, B. Wang, Q.-X. Deng, Z.-W. Zhu, and F. Xiao, "Model experimental study on stress transfer and redistribution in a clay landslide under surcharge load," Advances in Materials Science and Engineering, vol. 2020, Article ID 4269043, 14 pages, 2020.

[3] C. I. Tsai and Y. C. Shiau, "Research on landslide disaster causes and preventive methods of highway-3 in Taiwan," Disaster Advances, vol. 5, no. 4, pp. 398-403, 2012.

[4] L. Tang, M. Zhong, Z. Zhao et al., "The model test of landslide and its evolution law analysis," Industrial Construction, vol. 49, no. 5, pp. 75-80, 2019, in Chinese.

[5] T. Ito and T. Matsui, "Methods to estimate lateral force acting on stabilizing piles," Soils And Foundations, vol. 15, no. 4, pp. 43-59, 1975. 
[6] H. Matlock, "Correlations for design of laterally loaded piles in soft clay," in Proceedings of the 2nd Offshore Technology Conference, pp. 577-591, Houston, TX, USA, 1970.

[7] H. G. Poulos, "Design of reinforcing piles to increase slope stability," Canadian Geotechnical Journal, vol. 32, no. 5, pp. 808-818, 1995.

[8] A. Abdelaziz, D. Hafez, and A. Hussein, "The effect of pile parameters on the factor of safety of piled-slopes using $3 \mathrm{D}$ numerical analysis," HBRC Journal, vol. 13, no. 3, pp. 277-285, 2017.

[9] R. Kourkoulis, F. Gelagoti, I. Anastasopoulos, and G. Gazetas, "Slope stabilizing piles and pile-groups: parametric study and design insights," Journal of Geotechnical and Geoenvironmental Engineering, vol. 137, no. 7, pp. 663-677, 2011.

[10] R. Kourkoulis, F. Gelagoti, I. Anastasopoulos, and G. Gazetas, "Hybrid method for analysis and design of slope stabilizing piles," Journal of Geotechnical and Geoenvironmental Engineering, vol. 138, no. 1, pp. 1-14, 2012.

[11] S. Xiao, "A simplified approach for stability analysis of slopes reinforced with one row of embedded stabilizing piles," Bulletin of Engineering Geology and the Environment, vol. 76, no. 4, pp. 1371-1382, 2017.

[12] R. Frank and P. Pouget, "Experimental pile subjected to long duration thrusts owing to a moving slope," GéotechniqueGéotechnique, vol. 58, no. 8, pp. 645-658, 2008.

[13] A. Galli and A. Bassani, "Innovative performance-based design of slope stabilizing piles for a railway embankment," European Journal of Environmental and Civil Engineering, vol. 22, no. 1, pp. 99-121, 2018.

[14] J. A. Smethurst and W. Powrie, "Monitoring and analysis of the bending behaviour of discrete piles used to stabilise a railway embankment," GéotechniqueGéotechnique, vol. 57, no. 8, pp. 663-677, 2007.

[15] Z. Bo, Y.-S. Wang, W. Yu, S. Tong, and Z. Yong-Chao, "Retaining mechanism and structural characteristics of h type slide-resistant pile (hTP pile) and experience with its engineering applicationRetaining mechanism and structural characteristics of $\mathrm{h}$ type anti-slide pile (hTP pile) and experience with its engineering application," Engineering Geology, vol. 222, pp. 29-37, 2017.

[16] H. G. Poulos, "Behaviour of laterally loaded piles near a cut or slope," Australian Geomechanics Journal, vol. 6, no. 1, pp. 6-12, 1977.

[17] D. Rathod, K. Muthukkumaran, and T. G. Sitharam, "Effect of slope on $p-y$ curves for laterally loaded piles in soft clay," Geotechnical and Geological Engineering, vol. 36, no. 3, pp. 1509-1524, 2018.

[18] S. V. Sivapriya and S. R. Gandhi, "Experimental and numerical study on pile behaviour under lateral load in clayey slope," Indian Geotechnical Journal, vol. 43, no. 1, pp. 105-114, 2013.

[19] P. Yin, W. He, and Z. J. Yang, "A simplified nonlinear method for a laterally loaded pile in sloping ground," Advances in Civil Engineering, vol. 2018, Article ID 5438618, 9 pages, 2018.

[20] S. Mezazigh and D. Levacher, "Laterally loaded piles in sand: slope effect on P-Y reaction curves," Canadian Geotechnical Journal, vol. 35, no. 3, pp. 433-441, 1998.

[21] K. Sawada and J. Takemura, "Centrifuge model tests on piled raft foundation in sand subjected to lateral and moment loads," Soils and Foundations, vol. 54, no. 2, pp. 126-140, 2014.

[22] K. Georgiadis, M. Georgiadis, and C. Anagnostopoulos, "Lateral bearing capacity of rigid piles near clay slopes," Soils and Foundations, vol. 53, no. 1, pp. 144-154, 2013.
[23] V. K. Chandaluri and V. A. Sawant, "Effect of slope angle on pile response," Indian Journal of Science and Technology, vol. 9, no. 48, 2017.

[24] K. Georgiadis and M. Georgiadis, "Undrained lateral pile response in sloping ground," Journal of Geotechnical and Geoenvironmental Engineering, vol. 136, no. 11, pp. 1489$1500,2010$.

[25] C. W. W. Ng and L. M. Zhang, "Three-dimensional analysis of performance of laterally loaded sleeved piles in sloping ground," Journal of Geotechnical and Geoenvironmental Engineering, vol. 127, no. 6, pp. 499-509, 2001.

[26] H. Yuan and Y. Li, "Downdrag Force Analysis for Seismic Soil-Pile-Structure InteractionDowndrag force analysis for seismic soil-pile-structure interaction," Geotechnical and Geological Engineering, vol. 35, no. 1, pp. 493-501, 2017.

[27] H. Elahi, H. G. Poulos, H. Hajimollaali, and A. Elahi, "Pseudostatic seismic response analysis of a pile group in a soil slope," Geotechnical and Geological Engineering, vol. 36, no. 2, pp. 855-874, 2018.

[28] A. Tabesh and H. G. Poulos, "Pseudostatic approach for seismic analysis of single piles," Journal of Geotechnical and Geoenvironmental Engineering, vol. 127, no. 9, pp. 757-765, 2001.

[29] L. P. Wang and G. Zhang, "Centrifuge model test study on pile reinforcement behavior of cohesive soil slopes under earthquake conditions," Landslides, vol. 11, no. 2, pp. 213-223, 2014.

[30] N. Nimityongskul, Y. Kawamata, D. Rayamajhi, and S. A. Ashford, "Full-scale tests on effects of slope on lateral capacity of piles installed in cohesive soils," Journal of Geotechnical and Geoenvironmental Engineering, vol. 144, no. 1, Article ID 04017103, 2018.

[31] A. D. Mirzoyan, Lateral Resistance of Piles at the Crest of Slopes in Sand, Brigham Young University, Provo, UT, USA, 2007.

[32] P. A. Cundall, "Distinct element models of rock and soil structure," in Analytical and Computational Methods in Engineering Rock Mechanics, E. T. Brown, Ed., pp. 129-163, Allen \& Unwin, London, UK, 1987.

[33] Q. Jiang, Z. Qi, W. Wei, and C. Zhou, "Stability assessment of a high rock slope by strength reduction finite element method," Bulletin of Engineering Geology and the Environment, vol. 74, no. 4, pp. 1153-1162, 2015.

[34] T.-K.T. K. Nian, R.-Q.R. Q. Huang, S.-S.S. S. Wan, and G.-Q.G. Q. Chen, "Three-dimensional strength-reduction finite element analysis of slopes: geometric effects," Canadian Geotechnical Journal, vol. 49, no. 5, pp. 574-588, 2012.

[35] Y. Li, L. Yu, W. Song, and T. Yang, "Three-dimensional analysis of complex rock slope stability affected by fault and weak layer based on FESRM," Advances in Civil Engineering, vol. 2019, Article ID 6380815, 14 pages, 2019.

[36] G. Shi, Y. Wang, Y. Wang, Z. Tao, L. Wan, and L. Xi, "Numerical analysis and deformation mechanism study on an excavated high-steep slope of a hydropower station," Advances in Civil Engineering, vol. 2020, Article ID 3402762, 17 pages, 2020. 